Discussion Paper Series A No.558

\title{
Optimal Monetary Policy in an Estimated Local Currency Pricing Model
}

\author{
Okano Eiji \\ (Faculty of Economics, Chiba Keizai University) \\ Masataka Eguchi \\ (Faculty of Economics, Keio University) \\ Hiroshi Gunji \\ (Faculty of Economics, Daito Bunka University) \\ and \\ Tomomi Miyazaki \\ (Institute of Economic Research, Hitotsubashi University \\ and Faculty of Economics, Toyo University) \\ January 2012 \\ Institute of Economic Research \\ Hitotsubashi University \\ Kunitachi, Tokyo, 186-8603 Japan
}




\title{
Optimal Monetary Policy in an Estimated Local Currency Pricing Model*
}

\author{
Okano, Eiji ${ }^{\dagger}$, Masataka Eguchi ${ }^{\ddagger}$, Hiroshi Gunji ${ }^{\S}$ \\ and \\ Tomomi Miyazaki $₫$
}

This Draft: Jan., 2012

\begin{abstract}
We analyze fluctuations in inflation and the nominal exchange rate under optimal monetary policy with local currency pricing by developing two-country DSGE local currency pricing and producer currency pricing models. We estimate our models using Bayesian techniques with Japanese and US data, and calculate impulse response functions. Our estimation results show that local currency pricing is strongly supported against producer currency pricing. From the estimated parameters, we show that completely stabilizing consumer price index inflation is optimal from the viewpoint of minimizing welfare costs and that completely stabilizing consumer price index inflation is consistent with completely stabilizing the nominal exchange rate.
\end{abstract}

Keywords: local currency pricing, optimal monetary policy, CPI inflation, fixed exchange rate, Bayesian estimation

JEL Classification: E52; E62; F41

\footnotetext{
*We would like to thank Andrea Ferrero, Carter Hill, Chikafumi Nakamura, Efrem Castelnuovo, Eiji Ogawa, Fabio Milani, Ivan Jeliazkov, Martin Fukac, Tae-Sok Jang, Tom Fomby and seminar and conference participants at Hitotsubashi University, National Graduate Institute for Policy Studies, Southern Methodist University and Vanderbilt University. All errors are my own. This research is financially assisted by the Zengin Foundation for Studies on Economics and Finance.

$\dagger$ Corresponding Author. Faculty of Economics, Chiba Keizai University, 59-5, Todorokicho 3-chome, Inage-ku, Chiba-shi, Chiba, 263-0021, Japan. Tel: +81-43-253-9725; Fax: +81-43254-6600; e-mail: e.okano@cku.ac.jp

${ }^{\ddagger}$ Faculty of Economics, Keio University, Tokyo, Japan

$\S$ Faculty of Economics, Daito Bunka University, Tokyo, Japan

ฯInstitute of Economic Research, Hitotsubashi University, Tokyo, Japan / Faculty of Economics, Toyo University, Tokyo, Japan
} 


\section{Introduction}

What kind of inflation rate should be stabilized from the viewpoint of minimizing welfare costs? Which exchange rate regime should be chosen from that viewpoint? These are important questions when discussing optimal monetary policy in an open economy. This paper shows that consumer price index (CPI) inflation should be stabilized if we assume that prices are set in the consumers' currency (denoted local currency pricing, LCP). In addition, we show that stabilizing the CPI inflation rate is not inconsistent with a fixed exchange rate under LCP. Our finding contrasts with previous papers discussing optimal monetary policy using dynamic stochastic general equilibrium (DSGE) models because those papers show that the producer price index (PPI) inflation rate should be stabilized from that viewpoint even if an open economy is assumed. ${ }^{1}$ Gali and Monacelli [12] show that optimal monetary policy in a small open economy is consistent with PPI inflation targeting. ${ }^{2}$ Although not mentioned explicitly, they assume that prices are set in the producers' currency (denoted producer currency pricing, PCP). They compare three policy regimes, PPI inflation-based and CPI inflation-based Taylor rules and a fixed exchange rate regime, and show that of these three regimes a PPI inflation-based Taylor rule produces macroeconomic volatility closest to that brought about by optimal monetary policy. In addition, their policy implications suggest that the optimal monetary policy outcome is not fundamentally different from the closed economy outcome. While they do not highlight firms' price-setting behavior, Gali and Monacelli [12] imply that PPI inflation targeting is optimal under PCP. Developing a twocountry model, Benigno and Benigno [2] show implicitly that stabilizing PPI inflation minimizes welfare costs under PCP.

Reflecting on LCP, which cannot be ignored because of supporting empirical evidence, some studies in the new open economy macroeconomics (NOEM) literature and DSGE literature focus on LCP to discuss monetary policy. Introducing importers adopting LCP into Gali and Monacelli's [12] model, Monacelli [25] shows that the law of one price (LOOP) gap resembles a cost-push shock to the New Keynesian Philips Curve (NKPC) and implies that inflation-output gap tradeoffs cannot be dissolved by optimal monetary policy, although Gali and Monacelli [12] suggest that those tradeoffs can be dissolved. Because of the appearance of a LOOP gap in the NKPC, he emphasizes that optimal monetary policy stabilizes the LOOP gap. ${ }^{3}$ Devereux, Lane and Xu [6] show that CPI price stability maximizes households' utility, rather than nontradable goods price stability and a fixed exchange rate regime, in a model in which external shocks affect an emerging market via changes in interest rates and the terms of trade (TOT) by introducing financial frictions, a nontraded goods sector and importers adopting LCP. Devereux and Engel [5] show that a fixed exchange rate regime minimizes welfare costs with their two-country model with LCP firms. While Devereux, Lane and $\mathrm{Xu}[6]$ consider a targeted inflation rate, Devereux and Engel [5] consider a fixed exchange rate regime. In addition, only

\footnotetext{
${ }^{1}$ In many DSGE studies, there is no distinction between the definitions of PPI inflation, domestic inflation and GDP inflation.

${ }^{2}$ Gali and Monacelli [12] term the Taylor rule which includes PPI inflation a domestic inflation-based Taylor rule rather than a PPI inflation-based Taylor rule. However, their definition of domestic inflation is consistent with our definition of PPI inflation.

${ }^{3}$ Note that Monacelli [25] does not analyze optimal monetary policy explicitly.
} 
Devereux and Engel [5] discuss optimal monetary policy explicitly. Hence, the type of inflation rate that should be stabilized from the viewpoint of minimizing welfare costs and the relationship between the exchange rate regime and optimal monetary policy is ambiguous. ${ }^{4}$ Focusing on policy tradeoffs between stabilization of the prices of domestically produced goods and stabilization of the prices of imported goods, Corsetti, Dedola and Leduc [3] show that CPI stabilization is optimal from the viewpoint of maximizing households' utility. Their LCP model is quite sophisticated, because they introduce both upstream and downstream firms to generate policy tradeoffs between stabilization of the prices of domestically produced goods and stabilization of the prices of imported goods. They compare various policy regimes and show that strict CPI inflation targeting is close to optimal monetary policy in its effect on the volatility of the CPI inflation rate and real GDP. This result suggests that CPI stabilization is optimal from the viewpoint of minimizing welfare costs under LCP. However, they imply that complete stabilization in the nominal exchange rate is not consistent with complete CPI stabilization. ${ }^{5}$ In addition, they do not clarify the relationship between inflation and the output gap.

To identify the type of inflation rate that should be stabilized under LCP and to clarify the relationship between the optimal targeted inflation rate and the exchange rate regime, we develop an LCP model that assumes a two-country setting at first. In addition, to clarify what affects differences in the policy implications of LCP, we also develop a two-country model with PCP, following studies such as Gali and Monacelli [12] and Benigno and Benigno [2]. We estimate both models with a plausible interest rate feedback rule adopting Bayesian techniques as in Smets and Wouters [31], Adjemian, Darracq-Paries and Smets [1] and Rabanal and Tuesta [29] using Japanese and US data, and compare the plausibility of the two models. Well-microfounded loss functions under both LCP and PCP are derived from a second-order Taylor expanded utility function following Woodford [34] and Gali [11]. We derive optimality conditions for central banks that minimize microfounded loss functions and simulate the LCP and PCP models with estimated posterior parameters.

Our estimation results for the PCP and LCP models are consistent with previous papers. Following Kass and Raftery [19] and Jeffreys [17] by comparing the LCP and PCP models, we find that the LCP model is more plausible than the PCP model. This finding is consistent with Engel and Rogers [7], Goldberg and Knetter [13] and Frankel, Parseley and Wei [9], who show that LCP is dominant. ${ }^{6}$

Our most important result is that optimal monetary policy under LCP produces no fluctuations in the CPI inflation rate. The PPI inflation rate is not stabilized under LCP. Roughly speaking, optimal monetary policy under LCP is CPI inflation targeting. This result is quite different from the result in Gali and Monacelli [12]. Our result is confirmed by the IRFs, volatility in the CPI inflation and the loss function stemming from a second-order approximated utility

\footnotetext{
${ }^{4}$ In fact, Devereux and Engel [5] do not discuss fluctuations in the inflation rate under a fixed exchange rate that minimize welfare costs under the LCP, and Devereux, Lane and $\mathrm{Xu}$ [6] imply that there is a tradeoff between CPI stabilization and nominal exchange rate stabilization.

${ }^{5}$ In fact, they state that complete CPI stabilization may not be desirable.

${ }^{6}$ Engel and Rogers [7], Goldberg and Knetter [13] and Frankel, Parseley and Wei [9] report a high degree of stability in import prices in the local currency.
} 
function. Interestingly, the quadratic terms of CPI inflation appear in our loss function and replace the quadratic terms of PPI inflation under LCP, although the quadratic terms of PPI inflation appear in our loss function under PCP as in Gali and Monacelli [12] and Benigno and Benigno [2].

Our result that there are no fluctuations in the nominal exchange rate under LCP is consistent with Devereux and Engel [5]. Another result, that there are no fluctuations in CPI inflation under LCP, is consistent with Corsetti, Dedola and Leduc [3]. Summarizing our results, optimal monetary policy under LCP is not only consistent with CPI inflation targeting but also consistent with a fixed exchange rate. Hence, it can be said that we reconcile with Devereux and Engel [5], who show that a fixed exchange rate regime is optimal, and with Corsetti, Dedola and Leduc [3], who show that CPI stabilization is optimal and there is a strong stabilization tradeoff between the nominal exchange rate and CPI inflation.

The rest of this paper is organized as follows. Section 2 derives the LCP and PCP models. Section 3 estimates the LCP and PCP models using Bayesian techniques. Section 4 analyzes optimal monetary policy by deriving welfare costs and FONCs for central banks, and simulates the models. Section 5 concludes the paper.

\section{The Model}

We construct a two-country model belonging to the class of DSGE models with nominal rigidities and imperfect competition, basically following Gali and Monacelli [12] and Monacelli [25]. We extend Gali and Monacelli's [12] small open economy model to develop a two-country economy model following Obstfeld and Rogoff [27], although we assume all goods are tradable. The economy consists of two symmetric countries, $H$ and $F$. Country $H$ produces an array of differentiated goods indexed by the interval $h \in[0,1]$, while country $F$ produces an array of differentiated goods indexed by $f \in[1,2]$. In addition, we derive two models; one of them adopts LCP, while the other adopts PCP.

Note that we define $v_{t} \equiv \ln \left(\frac{V_{t}}{V}\right)$ if there are no provisions, where $V_{t}$ denotes an arbitrary variable and $V$ denotes the steady state value of $V_{t}$.

\subsection{LCP Model}

Under LCP, the LOOP does not necessarily hold because firms can choose the prices at which to sell goods in countries $H$ and $F$ separately. Thus, $P_{t}(h)=\mathcal{E}_{t} P_{t}^{*}(h)$ and $P_{t}(f)=\mathcal{E}_{t} P_{t}^{*}(f)$ hence $P_{H, t}=\mathcal{E}_{t} P_{H, t}^{*}$ and $P_{F, t}=$ $\mathcal{E}_{t} P_{F, t}^{*}$ do not necessarily hold where $P_{t}(h)$ and $P_{t}(f)$ denote the price of a generic good produced in country $H$ in terms of country $H$ 's currency, $P_{H, t} \equiv$ $\left[\int_{0}^{1} P_{t}(h)^{1-\varepsilon} d h\right]^{\frac{1}{1-\varepsilon}}$ and $P_{F, t} \equiv\left[\int_{1}^{2} P_{t}(f)^{1-\varepsilon} d h\right]^{\frac{1}{1-\varepsilon}}$ denote indices of the prices of generic goods produced in countries $H$ and $F$, respectively, $\mathcal{E}_{t}$ denotes the nominal exchange rate and $\varepsilon>1$ denotes the elasticity of substitution across goods. ${ }^{7}$ Note that quantities and prices particular to country $F$ are denoted by asterisks, while quantities and prices without asterisks are those in country $H$.

\footnotetext{
${ }^{7}$ By citing Betts and Devereux [4], Mark [23] explains LCP clearly.
} 


\subsubsection{Households}

The preferences of the representative household in country $H$ are given by:

$$
\mathcal{U} \equiv \mathrm{E}_{0} \sum_{t=0}^{\infty} \beta^{t} U_{t},
$$

where $U_{t} \equiv \frac{1}{1-\sigma} C_{t}^{1-\sigma}-\frac{1}{1+\varphi} N_{t}^{1+\varphi}$ denotes the period utility, $\mathrm{E}_{t}$ denotes the expectation, conditional on the information set at period $t, \beta \in(0,1)$ denotes the subjective discount factor, $C_{t}$ denotes consumption, $N_{t} \equiv \int_{0}^{1} N_{t}(h) d h$ denotes hours of work, $\sigma$ denotes the degree of relative risk aversion and $\varphi$ denotes the inverse of the labor supply elasticity. The preferences of the representative household in country $F$ are defined analogously.

More precisely, private consumption is a composite index defined by:

$$
C_{t} \equiv\left[\left(\frac{1}{2}\right)^{\frac{1}{\eta}} C_{H, t}^{\frac{\eta-1}{\eta}}+\left(\frac{1}{2}\right)^{\frac{1}{\eta}} C_{F, t}^{\frac{\eta-1}{\eta}}\right]^{\frac{\eta}{\eta-1}}
$$

where $C_{H, t} \equiv\left[\int_{0}^{1} C_{t}(h)^{\frac{\varepsilon-1}{\varepsilon}} d h\right]^{\frac{\varepsilon}{\varepsilon-1}}$ and $C_{F, t} \equiv\left[\int_{1}^{2} C_{t}(f)^{\frac{\varepsilon-1}{\varepsilon}} d f\right]^{\frac{\varepsilon}{\varepsilon-1}}$ denote Dixit-Stiglitz-type indices of goods produced in countries $H$ and $F$, respectively, and $\eta>0$ denotes the elasticity of substitution between goods produced in countries $H$ and $F$. Note that $C_{t}^{*}$ is defined analogously to Eq. (2).

Total consumption expenditure by households in country $H$ is given by $P_{H, t} C_{H, t}+P_{F, t} C_{F, t}=P_{t} C_{t}$. A sequence of budget constraints in country $H$ is given by:

$$
B_{t}+W_{t} N_{t}-T_{t} \geq P_{t} C_{t}+\mathrm{E}_{t}\left(Q_{t, t+1} B_{t+1}\right),
$$

where $Q_{t, t+1}$ denotes the stochastic discount factor, $B_{t}$ denotes the nominal payoff of the bond portfolio purchased by households, $W_{t}$ denotes the nominal wage, and $T_{t}$ denotes lump-sum taxes. The budget constraint in country $F$ is given analogously. Furthermore:

$$
P_{t} \equiv\left(\frac{1}{2} P_{H, t}^{1-\eta}+\frac{1}{2} P_{F, t}^{1-\eta}\right)^{\frac{1}{1-\eta}}
$$

denotes the CPI. $P_{t}^{*}$ is defined analogously to this equation. Log-linearizing this equality yields $p_{t}=\frac{1}{2} p_{H, t}+p_{F, t}$, which implies the following:

$$
\pi_{t}=\frac{1}{2} \pi_{H, t}+\frac{1}{2} \pi_{F, t},
$$

where $\pi_{t} \equiv p_{t}-p_{t-1}$ denotes CPI inflation with $\pi_{H, t}=p_{H, t}-p_{H, t-1}$ and $\pi_{F, t}=p_{F, t}-p_{F, t-1}$.

The optimal allocation of any given expenditure within each category of goods implies the demand functions as follows:

$$
\begin{array}{ccc}
C_{t}(h)=\left(\frac{P_{t}(h)}{P_{H, t}}\right)^{-\varepsilon} C_{H, t} \quad ; \quad C_{t}(f)=\left(\frac{P_{t}(f)}{P_{F, t}}\right)^{-\varepsilon} C_{F, t} \\
C_{t}^{*}(h)=\left(\frac{P_{t}^{*}(h)}{P_{H, t}^{*}}\right)^{-\varepsilon} C_{H, t}^{*} \quad ; \quad C_{t}^{*}(f)=\left(\frac{P_{t}^{*}(f)}{P_{F, t}^{*}}\right)^{-\varepsilon} C_{F, t}^{*} .
\end{array}
$$


The optimal allocation of expenditures between domestic and foreign goods is given by:

$$
\begin{aligned}
C_{H, t} & =\frac{1}{2}\left(\frac{P_{H, t}}{P_{t}}\right)^{-\eta} C_{t} \quad ; & C_{F, t} & =\frac{1}{2}\left(\frac{P_{F, t}}{P_{t}}\right)^{-\eta} C_{t}, \\
C_{H, t}^{*} & =\frac{1}{2}\left(\frac{P_{H, t}^{*}}{P_{t}^{*}}\right)^{-\eta} C_{t}^{*} \quad ; & C_{F, t}^{*} & =\frac{1}{2}\left(\frac{P_{F, t}^{*}}{P_{t}^{*}}\right)^{-\eta} C_{t}^{*} .
\end{aligned}
$$

The representative household maximizes Eq. (1) subject to Eq. (3). The optimality conditions are given by:

$$
R_{t} \beta \mathrm{E}_{t}\left(\frac{C_{t+1}^{-\sigma} P_{t}}{C_{t}^{-\sigma} P_{t+1}}\right)=1,
$$

which is a conventional Euler equation and

$$
C_{t}^{\sigma} N_{t}^{\varphi}=\frac{W_{t}}{P_{t}}
$$

which is a standard intratemporal optimality condition where $R_{t} \equiv 1+r_{t}$ satisfying $R_{t}^{-1}=\mathrm{E}_{t} Q_{t, t+1}$ denotes the gross nominal return on a riskless one-period discount bond paying off one unit of the common currency (in short, the gross nominal interest rate), and $r_{t}$ denotes the net nominal interest rate. Eq. (8) is an intertemporal optimality condition, namely the Euler equation, and Eq. (9) is an intratemporal optimality condition. Optimality conditions in country $F$ are given analogously.

Log-linearizing Eq. (8), we obtain:

$$
c_{t}=\mathrm{E}_{t} c_{t+1}-\frac{1}{\sigma} \hat{r}_{t}+\frac{1}{\sigma} \mathrm{E}_{t} \pi_{t+1},
$$

with $\hat{r}_{t} \equiv \ln \left(\frac{R_{t}}{R}\right)$.

There is an uncovered interest rate parity (UIP) relationship for the gross nominal interest rate between countries $H$ and $F$ as follows:

$$
R_{t}=R_{t}^{*} \mathrm{E}_{t}\left(\frac{\mathcal{E}_{t+1}}{\mathcal{E}_{t}}\right)
$$

with $R_{t}^{*} \equiv 1+r_{t}^{*}$. Log-linearizing the UIP, we have the following familiar expression:

$$
\mathrm{E}_{t}\left(\Delta e_{t+1}\right)=\hat{r}_{t}-\hat{r}_{t}^{*}
$$

with $\Delta v_{t} \equiv v_{t}-v_{t-1}$ and $e_{t} \equiv \ln \left(\frac{\mathcal{E}_{t}}{\mathcal{E}}\right)$.

Combining Eq. (8) and UIP and iterating with an initial condition, we have the following optimal risk-sharing condition:

$$
C_{t}^{\sigma}=\vartheta\left(C_{t}^{*}\right)^{\sigma} \mathcal{Q}_{t},
$$

with $\mathcal{Q}_{t} \equiv \frac{\mathcal{E}_{t} P_{t}^{*}}{P_{t}}$ denoting the real exchange rate and $\vartheta$ denoting a constant depending on the initial value. Log-linearizing this equality, we have:

$$
c_{t}=c_{t}^{*}+\frac{1}{\sigma} q_{t}
$$


Our setting is definitely different from Betts and Devereux [4], who introduce pricing-to-market behavior that is consistent with LCP in our definition into the Redux model developed by Obstfeld and Rogoff [26]. Although Betts and Devereux [4] and this paper allow violations of the LOOP, purchasing power parity (PPP) holds in this paper ex post, although PPP does not necessarily hold in their paper. While we assume an international risk-sharing condition as shown in Eq. (11), Betts and Devereux [4] introduce restrictions in asset availability, which inhibits international optimal risk sharing. ${ }^{8}$ Because of their setting, Eq. (11) is no longer applied, hence PPP is not necessarily applied. In addition, this implies that violation of PPP does not stem from LCP. We further discuss the relationship between the LOOP and PPP under LCP in Section 2.1.3.

\subsubsection{Market Clearing}

The market for goods in country $H$ satisfies the market clearing condition when domestic demand equals domestic supply, as follows:

$$
Y_{t}(h)=C_{t}(h)+C_{t}^{*}(h),
$$

where $Y_{t}(h)$ denotes the output of good $h$. The market clearing condition in country $F$ is analogous. Substituting Eq. (6) into Eq. (12) yields:

$$
Y_{t}(h)=\frac{1}{2}\left(\frac{P_{t}(h)}{P_{H, t}}\right)^{-\varepsilon}\left(\frac{P_{H, t}}{P_{t}}\right)^{-\eta} C_{t}+\frac{1}{2}\left(\frac{P_{t}^{*}(h)}{P_{H, t}^{*}}\right)^{-\varepsilon}\left(\frac{P_{H, t}^{*}}{P_{t}^{*}}\right)^{-\eta} C_{t}^{*} .
$$

Let $Y_{t} \equiv\left[\int_{0}^{1} Y_{t}(h)^{\frac{\varepsilon-1}{\varepsilon}} d h\right]^{\frac{\varepsilon}{\varepsilon-1}}$ represent the index of aggregate output in country $H$. Under LCP, we obtain:

$$
\begin{aligned}
Y_{t} & =\frac{1}{2}\left(\frac{P_{H, t}}{P_{t}}\right)^{-\eta} C_{t}+\frac{1}{2}\left(\frac{P_{H, t}^{*}}{P_{t}^{*}}\right)^{-\eta} C_{t}^{*}, \\
& =\frac{1}{2}\left(\frac{P_{H, t}}{P_{t}}\right)^{-\eta} C_{t}\left[1+\left(\frac{P_{H, t}}{P_{t}}\right)^{\eta}\left(\frac{P_{H, t}^{*}}{P_{t}^{*}}\right)^{-\eta} \mathcal{Q}_{t}^{-\frac{1}{\sigma}}\right],
\end{aligned}
$$

by combining Eq. (13) and the Dixit-Stiglitz aggregators for output and prices, where we substitute the optimal risk sharing condition into the first equality in Eq.(14) to derive the second line in Eq. (14).

We define the terms of trade (TOT) as follows:

$$
\mathcal{S}_{t} \equiv \frac{P_{F, t}}{\mathcal{E}_{t} P_{H, t}^{*}}
$$

where $\mathcal{S}_{t}$ is the foreign TOT. The numerator is the export price of goods produced in country $F$ in terms of country $H$ 's currency and the denominator is the export price of goods produced in country $F$ in terms of country $H$ 's currency. Log-linearizing Eq. (15), we have:

$$
s_{t}=p_{F, t}-e_{t}-p_{H, t}^{*}
$$

\footnotetext{
${ }^{8}$ Although they develop a two-country model that consists of a home and a foreign country internationally tradable assets are denominated in the home country's currency.
} 
where $s_{t} \equiv \ln \mathcal{S}_{t}$.

By log-linearizing Eq. (14), we have:

$$
y_{t}=c_{t}+\frac{\eta}{2} s_{t}+\frac{1}{2}\left(\eta-\frac{1}{\sigma}\right) q_{t}
$$

which is log-linearized market clearing in country $H$ under LCP. There is a difference between this equality and Eq. (42) because the logarithmic real exchange rate $q_{t}$ appears in this equality. However, this equality is equivalent to Eq. (42) because PPP holds, which implies that $q_{t}=0$, although we assume LCP.

Combining log-linearized market clearing in country $H$ and its counterpart in country $F$, we have:

$$
s_{t}=\frac{1}{\eta}\left(y_{t}-y_{t}^{*}\right)-q_{t}
$$

which clarifies the relationship between the TOT and relative output under LCP. As mentioned, $q_{t}=0$ holds, although we assume LCP. Hence, this equality is equivalent to Eq. (41).

\subsubsection{Firms}

Each producer uses a linear technology to produce a differentiated good as follows:

$$
Y_{t}(h)=A_{t} N_{t}(h),
$$

where $A_{t}$ denotes stochastic productivity in country $H$. Firms in country $F$ have a technology analogous to that of firms in country $H$. The percentage deviation of productivity from its steady state value in countries $H$ and $F$ follows $\operatorname{AR}(1)$ processes $a_{t}=\rho a_{t-1}+\xi_{t}$ and $a_{t}^{*}=\rho a_{t-1}^{*}+\xi_{t}^{*}$ with $\xi_{t}$ and $\xi_{t}^{*}$ being i.i.d. shocks.

Using Dixit-Stiglitz aggregators, Eq. (17) can be rewritten as:

$$
N_{t}=\frac{Y_{t} D_{t}}{A_{t}}
$$

with $D_{t} \equiv \int_{0}^{1} \frac{Y_{t}(h)}{Y_{t}} d h$. Because $d_{t}$ is $o\left(\|\xi\|^{2}\right)$, a first-order approximation of this equality is given by:

$$
y_{t}=a_{t}+n_{t},
$$

which is consistent with Gali and Monacelli's [12] log-linearized production function.

Following many DSGE studies including Gali and Monacelli [12], we assume that firms set prices using Calvo-Yun-style price-setting behavior. Hence, $1-\theta$ firms set new prices in each period, with an individual firm's probability of reoptimizing in any given period being independent of the time elapsed since it last set its prices. Each producer produces a single differentiated good and prices its good to reflect the elasticity of substitution across goods produced given the CPI. This is because each firm plays an active part in the monopolistically competitive market. In addition, we assume that firms have the ability to 
engage in price discrimination by setting a domestic price in terms of domestic currency for domestic sales that differs from the price that it sets for exports. This is LCP behavior. Under Calvo-Yun-style price-setting behavior and LCP behavior in a monopolistically competitive market, the maximization problems faced by producers in country $H$ are as follows:

$$
\begin{aligned}
\max _{\tilde{P}_{H, t}, \tilde{P}_{H, t}^{*}} \sum_{k=0}^{\infty} \theta^{k} \mathrm{E}_{t}\left\{Q_{t, t+k}\right. & {\left[\tilde{P}_{H, t}\left(\frac{\tilde{P}_{H, t}}{P_{H, t+k}}\right)^{-\varepsilon} C_{H, t+k}+\mathcal{E}_{t+k} \tilde{P}_{H, t}^{*}\left(\frac{\tilde{P}_{H, t}^{*}}{P_{H, t+k}^{*}}\right)^{-\varepsilon} C_{H, t+k}^{*}\right.} \\
& \left.\left.-M C_{t+k}^{n}\left(\left(\frac{\tilde{P}_{H, t}}{P_{H, t+k}}\right)^{-\varepsilon} C_{H, t+k}+\left(\frac{\tilde{P}_{H, t}^{*}}{P_{H, t+k}^{*}}\right)^{-\varepsilon} C_{H, t+k}^{*}\right)\right]\right\},
\end{aligned}
$$

where $\tilde{P}_{H, t}$ and $\tilde{P}_{H, t}^{*}$ are the prices chosen by firms when they have an opportunity to change the prices of goods produced and sold in country $H$ and goods produced in country $H$ and sold in country $F$, respectively, $M C_{t}^{n} \equiv P_{P, t} M C_{t}$ denotes nominal marginal costs in country $H$, and $M C_{t} \equiv \frac{(1-\tau) W_{t}}{A_{t} P_{P, t}}$ and $P_{P, t}$ denotes the PPI in country $H$, which is defined as follows:

$$
P_{P, t} \equiv \frac{P_{H, t} C_{H, t}+\mathcal{E}_{t} P_{H, t}^{*} C_{H, t}^{*}}{C_{H, t}+C_{H, t}^{*}},
$$

which can be rewritten as $P_{P, t}=P_{H, t}$ when the LOOP holds. The PPI in country $F$ is defined analogously. By log-linearizing this equality, we have $p_{P, t}=$ $\frac{1}{2} p_{H, t}+\frac{1}{2}\left(e_{t}+p_{H, t}^{*}\right)$, which implies the following:

$$
\pi_{P, t}=\frac{1}{2} \pi_{H, t}+\frac{1}{2}\left(\Delta e_{t}+\pi_{H, t}^{*}\right),
$$

where $\pi_{P, t}$ denotes the PPI inflation rate in country $H, \pi_{H, t} \equiv p_{H, t}-p_{H, t-1}$ denotes the inflation rate of goods both produced and sold in country $H, \pi_{H, t}^{*} \equiv$ $p_{H, t}^{*}-p_{H, t-1}^{*}$ denotes the inflation rate of goods produced in country $H$ and sold in country $F$, respectively and $\pi_{P_{t}}=\pi_{H, t}$ holds when the LOOP holds.

Note that the maximization problems that producers in country $F$ face are analogous to Eq. (20). Because of nominal rigidities, Eq. (20) looks complicated. When there are no nominal rigidities, namely $\theta \rightarrow 0$, Eq. (20) is equivalent to:

$$
\max _{P_{H, t}, P_{H, t}^{*}} P_{H, t} C_{H, t}+\mathcal{E}_{t} P_{H, t}^{*} C_{H, t}^{*}-M C_{t}^{n}\left(C_{H, t}+C_{H, t}^{*}\right),
$$

which implies that each firm sets its price in terms of the local currency in which each firm's good is sold and pays costs to produce in terms of the producer's currency. Under LCP, we have multiple FONCs because firms can choose $\tilde{P}_{H, t}$ and $\tilde{P}_{H, t}^{*}$ separately. The FONCs for Eq. (20) are as follows:

$$
\begin{array}{r}
\mathrm{E}_{t}\left[\sum_{k=0}^{\infty} \theta^{k} Q_{t, t+k}\left(\tilde{P}_{H, t}-\zeta M C_{t+k}^{n}\right)\left(\frac{\tilde{P}_{H, t}}{P_{H, t+k}}\right)^{-\varepsilon} C_{H, t+k}\right]=0, \\
\mathrm{E}_{t}\left[\sum_{k=0}^{\infty} \theta^{k} Q_{t, t+k}\left(\tilde{P}_{H, t}^{*} \mathcal{E}_{t+k}-\zeta M C_{t+k}^{n}\right)\left(\frac{\tilde{P}_{H, t}^{*}}{P_{H, t+k}^{*}}\right)^{-\varepsilon} C_{H, t+k}^{*}\right]=0,
\end{array}
$$


which can be log-linearized as follows:

$$
\begin{aligned}
& \tilde{p}_{H, t}=(1-\beta \theta) \sum_{k=0}^{\infty}(\beta \theta)^{k} \mathrm{E}_{t}\left(m c_{t+k}^{n}\right), \\
& \tilde{p}_{H, t}^{*}=(1-\beta \theta) \sum_{k=0}^{\infty}(\beta \theta)^{k} \mathrm{E}_{t}\left(m c_{t+k}^{n}-e_{t+k}\right),
\end{aligned}
$$

with $\zeta \equiv \frac{\theta}{\theta-1}$ denoting a constant markup where we use the fact that $Q_{t, t+k}=$ $\beta^{k}\left(\frac{C_{t+k}}{C_{t}}\right)^{-\sigma} \frac{P_{t}}{P_{t+k}}$. FONCs for firms imply that firms set the price as a markup over a weighted average of expected future marginal costs. In particular, the first equality in Eq. (22) corresponds to the one derived by Gali and Monacelli [12]. The second equality in Eq. (22) is not a familiar expression, although it implies that firms set the price as a markup over a weighted average of expected future nominal marginal costs. The second equality in Eq. (22) is the log-linearized FONC for firms that produce goods in country $H$ and sell them in country $F$. Those firms set the price in terms of country $F$ 's currency as a markup over a weighted average of expected future nominal marginal costs in terms of country F's currency. Next, we examine Eq. (22) after first discussing some identities including the relative prices peculiar to LCP behavior.

Under LCP, the LOOP does not necessarily hold because of Eqs. (20) and (22), which imply that firms set the prices of their goods in terms of the local currency, namely LCP. Because of this, there is a LOOP gap, which measures the degree of pass-through. Now, we discuss the LOOP gap and the real exchange rate in the context of our model. Following Monacelli [25], we define the LOOP gap as follows:

$$
\Psi_{H, t} \equiv \frac{\mathcal{E}_{t} P_{H, t}^{*}}{P_{H, t}} ; \Psi_{F, t} \equiv \frac{\mathcal{E}_{t} P_{F, t}^{*}}{P_{F, t}},
$$

where $\Psi_{H, t}$ and $\Psi_{F, t}$ denote the LOOP gap for goods produced in countries $H$ and $F$, respectively. When the LOOP holds, we have $\Psi_{H, t}=\Psi_{F, t}=1$.

Combining Eq. (7), the optimal risk-sharing condition and the definition of the TOT yields:

$$
\Psi_{H, t}=\Psi_{F, t}^{-1} \mathcal{S}_{t}^{-1}\left(\frac{\mathcal{E}_{t} P_{F, t}^{*}}{P_{H, t}}\right) \mathcal{Q}_{t}^{-\frac{1}{\sigma \eta}}
$$

which implies that the LOOP gap is a function of the TOT, the real exchange rate and the relative price of goods consumed domestically. Because $\mathcal{S}_{t}^{-1}\left(\frac{\mathcal{E}_{t} P_{F, t}^{*}}{P_{H, t}}\right)=\Psi_{H, t} \Psi_{F, t}$, that equality can be rewritten as follows:

$$
\mathcal{Q}_{t}=1,
$$

which implies that PPP holds, although the LOOP does not hold. ${ }^{9}$ The loglinearized version of this equality is as follows:

$$
q_{t}=0 .
$$

${ }^{9}$ This equality implies that the marginal utility of consumption in country $H$ is identical to that in country $F$. Hence, the UIP can be derived by simply combining Eq. 8 and its counterpart in country $F$, although we describe that we assume the UIP in Section 2.1.1. 
In addition, substituting Eq. (23) into Eq. (11), we have $c_{t}=c_{t}^{*}$, which implies that the marginal utilities of consumption in the two countries are equal. In fact, households in both countries consume the same goods, although there is price discrimination. As mentioned, the LOOP does not necessarily hold, although Eq. (23) implies that the PPP is definitely applied. This sounds inconsistent at a glance. However, although the price of one good violates the LOOP, PPP holds when another good violates the LOOP inversely. In fact, substituting $\mathcal{Q}_{t}=1$ into that equality, we have $\Psi_{H, t}=\Psi_{F, t}^{-1}$ and the log-linearized version of this as follows:

$$
\psi_{H, t}=-\psi_{F, t},
$$

which implies that gains from price discrimination correspond to losses from price discrimination.

The log-linearized market clearing conditions in countries $H$ and $F$ clarify the relationship between the nominal exchange rate, price level and TOT. Substituting the log-linearized definition of the CPI into the log-linearized market clearing conditions yields:

$$
\begin{aligned}
e_{t} & =p_{t}-p_{t}^{*} \\
& =p_{P, t}-p_{P, t}^{*}+s_{t}, \\
& =p_{P, t}-p_{P, t}^{*}+\frac{1}{\eta}\left(y_{t}-y_{t}^{*}\right),
\end{aligned}
$$

where we use the log-linearized definition of PPI to derive the second line and Eq. (41) to derive the third line. Eq. (24) implies that the output differential between both countries affects the nominal exchange rate.

In turn, we examine Eq. (22), the log-linearized FONCs for firms under LCP. Using the definition of the LOOP gap, Eq. (22) can be rewritten as follows:

$$
\begin{aligned}
\tilde{p}_{H, t}= & p_{H, t-1}+\sum_{k=0}^{\infty}(\beta \theta)^{k} \mathrm{E}_{t}\left(\pi_{H, t+k}\right)+\frac{1-\beta \theta}{2} \sum_{k=0}^{\infty}(\beta \theta)^{k} \mathrm{E}_{t}\left(\psi_{H, t+k}\right) \\
& +(1-\beta \theta) \sum_{k=0}^{\infty}(\beta \theta)^{k} \mathrm{E}_{t}\left(m c_{t+k}\right), \\
\tilde{p}_{H, t}^{*}= & p_{H, t-1}^{*}+\sum_{k=0}^{\infty}(\beta \theta)^{k} \mathrm{E}_{t}\left(\pi_{H, t+k}^{*}\right)-\frac{1-\beta \theta}{2} \sum_{k=0}^{\infty}(\beta \theta)^{k} \mathrm{E}_{t}\left(\psi_{H, t+k}\right) \\
& +(1-\beta \theta) \sum_{k=0}^{\infty}(\beta \theta)^{k} \mathrm{E}_{t}\left(m c_{t+k}\right) .
\end{aligned}
$$

As mentioned, firms set the price as a markup over a weighted average of future marginal cost. In our LCP setting, those firms' sales are not measured by the PPI, because it is the weighted average of the prices of goods selling in both country $H$ and country $F$. However, real marginal cost is measured by the PPI, as shown in the definition of nominal marginal cost. That is, those firms obtain sales of $P_{H, t}$ and pay total costs of $P_{P, t}$ and the gap is $p_{P, t}-p_{H, t}=\frac{1}{2} \psi_{H, t}$, which implies that the gap corresponds to the LOOP gap in country $H$. Although the firms selling goods in country $H$ have no currency disparity in sales and payments, LCP behavior generates the LOOP gap. Thus, a weighted average 
of the expected future LOOP gap in country $H$ appears in the first equality in Eq. (25).

The price-setting behavior of the firms selling goods in country $F$ generates the LOOP gap, as does the behavior of firms that sell goods in country $H$. These exporters obtain their revenue from the sale of goods exported in terms of country F's currency and pay total costs in terms of country $H$ 's currency. Their sales are measured in terms of country $H$ 's currency. Hence, their sales in terms of country $F$ 's currency are multiplied by the nominal exchange rate. They pay total costs measured by the PPI, as do the firms selling goods in country $H$. The gap is calculated by $p_{P, t}-\left(p_{H, t}^{*}+e_{t}\right)=-\frac{1}{2} \psi_{H, t}$. Thus, a weighted average of the expected future LOOP gap in country $H$ appears in the second equality in Eq. (25), although the sign is contrary to the first equality. A similar mechanism works in firms in country $F$, not only for selling goods domestically but also for exporters. Although our LCP setting is different from Monacelli [25], who assumes a small open economy and importers, our LCP setting clearly generates the LOOP gap, and this setting affects the nature of the New Keynesian Philips Curve (NKPC) and the amount of social welfare stemming from a second-order approximated utility function.

\subsubsection{Marginal Cost and Natural Rate of Output}

Substituting Eq. (9) into the definition of marginal cost, we obtain:

$$
M C_{t}=(1-\tau) \frac{C_{t}^{\sigma} N_{t}^{\varphi}}{A_{t}}\left(\frac{P_{P, t}}{P_{t}}\right)^{-1},
$$

which is log-linearized as follows:

$$
m c_{t}=\sigma c_{t}+\varphi n_{t}+\frac{1}{2} s_{t}-a_{t},
$$

which is consistent with Gali and Monacelli's [12] log-linearized marginal cost.

Under the flexible price equilibrium, $M C_{t}=\frac{1}{\zeta}$, implying that the real marginal cost is constant and corresponds to the inverse of a constant markup. Using this fact and combining Eqs. (14), (18) and Eq. (26), we have the natural rate of output under LCP in country $H$ as follows:

$\bar{Y}_{t}=\frac{1}{2}\left\{\frac{P_{P, t}}{P_{t}} \frac{\zeta^{-1}}{1-\tau} A_{t}^{1+\varphi}\left(\frac{P_{H, t}}{P_{t}}\right)^{-\eta \sigma}\left[1+\left(\frac{P_{H, t}}{P_{t}}\right)^{\eta}\left(\frac{P_{H, t}^{*}}{P_{t}^{*}}\right)^{-\eta} \mathcal{Q}_{t}^{-\frac{1}{\sigma}}\right]^{\sigma}\right\}^{\frac{1}{\varphi+\sigma}} D_{t}^{-\frac{\varphi}{\varphi+\sigma}}$,

where $\bar{Y}_{t}$ denotes the natural rate of output in country $H$, which implies that the natural rate of output is a function not only of productivity but also of relative prices because of the open economy setting.

Before log-linearizing this equality, we define the output gap in country $H$ $x_{t}$ as the percentage deviation of output in country $H y_{t}$ from its natural level $\bar{y}_{t}$. This relationship can be written as:

$$
x_{t} \equiv y_{t}-\bar{y}_{t},
$$

which is consistent with Gali and Monacelli's [12] definition. The output gap in country $F$ is defined analogously to Eq. (28). 
Next, we log-linearize that equality. The log-linearized natural rate of output under LCP is given by:

$$
\bar{y}_{t}=\frac{\omega_{1} \omega_{2}}{\omega_{3}} a_{t}-\frac{(\sigma \eta-1) \omega_{2}}{\omega_{3}} a_{t}^{*}
$$

where $\omega_{1} \equiv \eta(\sigma+2 \varphi)+1, \omega_{2} \equiv 2 \eta(1+\varphi)$ and $\omega_{3} \equiv \omega_{1}^{2}-(\sigma \eta-1)^{2}$. Whereas Gali and Monacelli [12] regard foreign output as exogenous because of their small open economy setting, foreign output, namely output in country $F$, is endogenous in our two-country setting. Thus, productivity in country $F$ replaces foreign output in Eq. (29).

Next, we consider Eq. (27), which shows the percentage deviation of marginal cost from its steady state value. Substituting Eqs. (19) and (28) into Eq. (27) yields:

$$
m c_{t}=\frac{\omega_{1}}{2 \eta} x_{t}+\frac{\sigma \eta-1}{2 \eta} x_{t}^{*}
$$

which implies that real marginal cost in country $H$ is the sum of the output gap in the two countries.

\subsubsection{The Demand and Supply Sides}

Substituting log-linearized market clearing and Eqs. (28) and (29) into Eq. (10) yields the New Keynesian IS Curve (NKIS) as follows:

$$
x_{t}=\mathrm{E}_{t}\left(x_{t+1}\right)-\frac{2 \eta}{\sigma_{\alpha}} \hat{r}_{t}+\frac{2 \eta}{\sigma_{\alpha}} \mathrm{E}_{t}\left(\pi_{P, t+1}\right)+\frac{\sigma \eta-1}{\sigma_{\alpha}} \mathrm{E}_{t}\left(\Delta x_{t+1}^{*}\right)+\frac{2 \eta}{\sigma_{\alpha}} \bar{r}_{t},
$$

where $\bar{r}_{t} \equiv-\sigma_{\alpha} \frac{(1-\rho)(1+\varphi) \omega_{4}}{\omega_{3}} a_{t}-\sigma_{\alpha} \frac{(1-\rho)(\sigma \eta-1)(1+\varphi) \omega_{5}}{\omega_{3}} a_{t}^{*}$ denotes the natural rate of interest in country $H$ with $\sigma_{\alpha} \equiv \sigma \eta+1, \omega_{4} \equiv \omega_{1}-\frac{(\sigma \eta-1)^{2}}{\sigma_{\alpha}}$ and $\omega_{5} \equiv \frac{\omega_{1}}{\sigma_{\alpha}}-1$. The NKIS in country $F$, which is analogous to Eq. (31), can be derived using the counterparts of Eqs. (10), (28) and (29).

Eq. (31) looks like an ordinary NKIS in the DSGE literature at a glance, however, because of LCP, Eq. (31) has some distinguishing features. Substituting Eq. (21) into Eq. (31), NKIS under LCP can be rewritten as follows:

$$
\begin{aligned}
x_{t}= & \mathrm{E}_{t}\left(x_{t+1}\right)-\frac{2 \eta}{\sigma_{\alpha}} \hat{r}_{t}+\frac{\eta}{\sigma_{\alpha}} \mathrm{E}_{t}\left(\pi_{H, t+1}\right)+\frac{\eta}{\sigma_{\alpha}} \mathrm{E}_{t}\left(\pi_{H, t+1}^{*}\right)+\frac{\eta}{\sigma_{\alpha}} \mathrm{E}_{t}\left(\Delta e_{t+1}\right) \\
& +\frac{\sigma \eta-1}{\sigma_{\alpha}} \mathrm{E}_{t}\left(\Delta x_{t+1}^{*}\right)+\frac{2 \eta}{\sigma_{\alpha}} \bar{r}_{t} \\
= & \mathrm{E}_{t}\left(x_{t+1}\right)-\frac{\eta}{\sigma_{\alpha}} \hat{r}_{t}-\frac{\eta}{\sigma_{\alpha}} \hat{r}_{t}^{*}+\frac{\eta}{\sigma_{\alpha}} \mathrm{E}_{t}\left(\pi_{H, t+1}\right)+\frac{\eta}{\sigma_{\alpha}} \mathrm{E}_{t}\left(\pi_{H, t+1}^{*}\right) \\
& +\frac{\sigma \eta-1}{\sigma_{\alpha}} \mathrm{E}_{t}\left(\Delta x_{t+1}^{*}\right)+\frac{2 \eta}{\sigma_{\alpha}} \bar{r}_{t},
\end{aligned}
$$

where we use log-linearized UIP to derive the second line. As shown in the first line, changes in the expected nominal exchange rate affect the NKIS. The second line shows that not only the domestic nominal interest rate but also the foreign nominal interest rate appears in the NKIS. 
Substituting the log-linearized Calvo's pricing rule and Eq. (30) into Eq. (25), we have equalities that determine the dynamics of inflation as follows:

$$
\begin{aligned}
& \pi_{H, t}=\beta \mathrm{E}_{t}\left(\pi_{H, t+1}\right)+\frac{\lambda}{2} \psi_{H, t}+\frac{\lambda \omega_{1}}{2 \eta} x_{t}+\frac{\lambda(\sigma \eta-1)}{2 \eta} x_{t}^{*}, \\
& \pi_{H, t}^{*}=\beta \mathrm{E}_{t}\left(\pi_{H, t+1}^{*}\right)-\frac{\lambda}{2} \psi_{H, t}+\frac{\lambda \omega_{1}}{2 \eta} x_{t}+\frac{\lambda(\sigma \eta-1)}{2 \eta} x_{t}^{*},
\end{aligned}
$$

with $\lambda \equiv \frac{(1-\beta \theta)(1-\theta)}{\theta}$. The first equality is the inflation dynamics for goods sold domestically and the second equality is the inflation dynamics for goods exported. Because Eq. (33) is derived from Eq. (25), the FONCs for firms in country $H$, the third and fourth terms on the RHS that stem from the real marginal cost in country $H$, are consistent between the equalities. The signs of the second terms on the RHS are opposite in the two equalities. The reason is that the losses from price discrimination are compensated by the gains from price discrimination, and vice versa. The counterpart of Eq. (33) is derived from the counterpart of Eq. (25).

Substituting Eq. (33) into Eq. (21), we have the New Keynesian Philips Curve (NKPC) in country $H$ as follows:

$$
\pi_{P, t}=\beta \mathrm{E}_{t}\left(\pi_{P, t+1}\right)+\frac{\lambda \omega_{1}}{2 \eta} x_{t}+\frac{\lambda(\sigma \eta-1)}{2 \eta} x_{t}^{*}-\frac{\beta}{2} \mathrm{E}_{t}\left(\Delta e_{t+1}\right)+\frac{1}{2} \Delta e_{t},
$$

and substituting the counterpart of Eq. (33) into Eq. (21) yields the counterpart of this equality in country $F$. This NKPC features the appearance of changes in the nominal exchange rate. Gali and Monacelli [12] mention that full stabilization of domestic prices coincides with full stabilization of the output gap, namely $x_{t}=\pi_{H, t}=0$ for all $t$. In our model, their domestic prices correspond to the PPI and they assume fully exogenous foreign output, which implies that the percentage deviation of marginal cost from its steady state value is not affected by the percentage deviation of foreign output from its steady state value. That is, they claim that full stabilization of PPI implies that output is at its natural rate if we ignore the foreign output gap or assume $\sigma \eta=1$ in this equality. Even if we ignore the foreign output gap or assume $\sigma \eta=1$ in this equality, full stabilization of PPI does not necessarily imply that output is at its natural rate because of changes in the nominal exchange rate, as shown in the fourth and fifth terms on the RHS. Changes in the nominal exchange rate act as cost-push shocks under LCP. Thus, full stabilization of PPI no longer implies that output is at its natural rate if we ignore the foreign output gap or assume $\sigma \eta=1$. Substituting Eqs. (24), (29) and (28) into that equality, we can eliminate changes in the nominal exchange rate and obtain:

$$
\begin{aligned}
\pi_{P, t}= & \beta \mathrm{E}_{t}\left(\pi_{P, t+1}\right)+\beta \mathrm{E}_{t}\left(\pi_{P, t+1}^{*}\right)-\frac{\beta}{\eta} \mathrm{E}_{t}\left(x_{t+1}\right)+\frac{\beta}{\eta} \mathrm{E}_{t}\left(x_{t+1}^{*}\right)+\kappa_{\varpi} x_{t} \\
& -\kappa_{\varsigma} x_{t}^{*}-\pi_{P, t}^{*}-\frac{1}{\eta} x_{t-1}+\frac{1}{\eta} x_{t-1}^{*}+\omega_{6} a_{t}-\omega_{6} a_{t-1}-\omega_{6} a_{t}^{*}+\omega_{6} a_{t-1}^{*}
\end{aligned}
$$

with $\kappa_{\varpi} \equiv \frac{1+\beta+\lambda \omega_{1}}{\eta}, \kappa_{\varsigma} \equiv \frac{1+\beta-\lambda(\sigma \eta-1)}{\eta}, \omega_{6} \equiv \frac{\omega_{2} \varpi_{3}(\sigma+\varphi)}{\omega_{3}}$ and $\varpi_{3} \equiv 1+\beta(1-\rho)$. Exogenous shocks appear in Eq. (34), which shows that exogenous productivity affects PPI inflation. 
Monacelli [25] derives a CPI-based NKPC. Following Monacelli [25], we derive a CPI-based NKPC. Substituting the first equality in Eq. (33) and its counterpart in country $F$ into Eq. (5) yields:

$$
\pi_{t}=\beta \mathrm{E}_{t}\left(\pi_{t+1}\right)+\frac{\kappa_{\alpha}}{2} x_{t}+\frac{\kappa_{\alpha}}{2} x_{t}^{*},
$$

with $\kappa_{\alpha} \equiv \lambda(\sigma+\varphi)$. As mentioned by Gali and Monacelli [12], $\kappa_{\alpha}$ is consistent with the slope coefficient for a standard closed economy NKPC. Full stabilization of CPI inflation rather than PPI inflation implies that output is at its natural rate when the nominal interest rate in both countries absorbs the effects of changes in productivity in NKISs. Gali and Monacelli [12] demonstrate that a full stabilization of PPI inflation implies that output is at its natural level and there is no output gap in their non-LCP setting in a small open economy, as mentioned. However, our CPI-based NKPC Eq. (35) implies that full stabilization of CPI inflation implies that output is at its natural level and there is no output gap in our LCP setting in a two-country model. This can be understood alternatively and intuitively by comparing Eqs. (5) and (21). To derive Eq. (34), we use Eq. (21) implying that PPI inflation is affected by changes in the nominal exchange rate, while we use Eq. (5) to derive Eq. (35).

In addition, Eq. (35) contrasts with the CPI-based NKPC in Monacelli [25]. In his LCP setting, importers purchase foreign goods in terms of foreign currency while they sell foreign goods in terms of domestic currency. Because importers maximize their profits, the LOOP gap appears in the CPI-based NKPC in Monacelli [25]. Our LCP setting is quite different from Monacelli's [25] setting. Goods markets are fully partitioned, so there are no importers and each producer prices their goods in terms of consumers' currency. As mentioned in Section 2.1.3, the LOOP gap does not appear in Eq. (35), in contrast with Monacelli [25].

\subsection{PCP Model}

Under PCP, the LOOP holds, which is given by $P_{t}(h)=\mathcal{E}_{t} P_{t}^{*}(h)$ and $P_{t}(f)=$ $\mathcal{E}_{t} P_{t}^{*}(f)$, hence:

$$
P_{H, t}=\mathcal{E}_{t} P_{H, t}^{*} ; P_{F, t}=\mathcal{E}_{t} P_{F, t}^{*}
$$

and

$$
p_{H, t}=e_{t}+p_{H, t}^{*} ; p_{F, t}=e_{t}+p_{F, t}^{*},
$$

hold.

\subsubsection{Households}

The preferences of the representative household, the private consumption index, the optimal allocation of any given expenditure within each category of goods and the optimal allocation of expenditures between domestic and foreign goods are given by Eqs. (1), (2), (6) and (7), as in the LCP model. Because households face the same optimization problem, the intertemporal and intratemporal optimality conditions are given by Eqs. (8) and (9). UIP holds in the PCP model, hence the optimal risk-sharing condition holds in the PCP model. The log-linearized definition of the CPI, the intertemporal optimality condition and the risk-sharing condition are given by Eqs. (5), (10) and (11). 


\subsubsection{Market Clearing}

The market clearing condition is given by Eq. (12) as in the LCP model. Substituting Eqs. (6) and (7) into Eq.(12), we obtain Eq. (13). Because of the LOOP, Eq. (13) can be rewritten as:

$$
Y_{t}(h)=\left(\frac{P_{t}(h)}{P_{H, t}}\right)^{-\varepsilon}\left(\frac{P_{H, t}}{P_{t}}\right)^{-\eta} C_{t},
$$

by using Eq. (36). Substituting the Dixit-Stiglitz aggregator of output into this equality yields:

$$
Y_{t}=\left(\frac{P_{H, t}}{P_{t}}\right)^{-\eta} C_{t}
$$

which is a demand function consistent with that of Benigno and Benigno [2]. ${ }^{10}$

The definition of the TOT is given by Eq. (15). Substituting Eq. (36) into Eq. (15) yields:

$$
\mathcal{S}_{t}=\frac{P_{F, t}}{P_{H, t}}
$$

which is only applicable to the PCP model because Eq. (36) is not applicable to the LCP model.

Log-linearizing Eq. (39), we have:

$$
s_{t}=p_{F, t}-p_{H, t} .
$$

Eq. (40) is only applicable to the PCP model because Eq. (37) does not hold under LCP, as is true for Eq. (39).

Substituting Eq. (37) into log-linearized Eq. (14), we have:

$$
s_{t}=\frac{1}{\eta}\left(y_{t}-y_{t}^{*}\right),
$$

which clarifies the relationship between the TOT and relative output under PCP. Gali and Monacelli [12] and Benigno and Benigno [2], who assume PCP, derive the same equality.

Log-linearizing Eq. (38) yields:

$$
y_{t}=\frac{\eta}{2} s_{t}+c_{t},
$$

where we use Eq. (37). As mentioned, Eq. (42) is the final form of loglinearized market clearing under LCP in country $H$. The difference in pricesetting behavior between LCP and PCP does not affect market clearing.

\subsubsection{Firms}

Firms' technology is given by Eq. (17), which can be rewritten as Eq. (18). Thus, log-linearized technology is given by Eq. (19) as in the LCP model.

\footnotetext{
${ }^{10} \mathrm{We}$ do not include government expenditure. Thus, government expenditure does not appear in the equalities, although it appears in Benigno and Benigno [2].
} 
We assume Calvo-Yun-style price-setting behavior as in the LCP model. However, the maximization problem faced by firms under PCP is quite simple. Because of $\tilde{P}_{H, t}=\mathcal{E}_{t} \tilde{P}_{H, t}^{*}$ and Eq. (36), Eq. (20) can be rewritten as:

$$
\max _{\tilde{P}_{H, t}} \sum_{k=0}^{\infty} \theta^{k} \mathrm{E}_{t}\left\{Q_{t, t+k}\left[\left(\tilde{P}_{H, t}-M C_{t+k}^{n}\right)\left(\frac{\tilde{P}_{H, t}}{P_{H, t+k}}\right)^{-\varepsilon}\left(C_{H, t+k}+C_{H, t+k}^{*}\right)\right]\right\},
$$

which is common in studies assuming Calvo pricing. Substituting Eq. (36) into the definition of the PPI, we have $P_{P, t}=P_{H, t}$, and substituting Eq. (37) into Eq. (21) yields:

$$
\pi_{P, t}=\pi_{H, t} .
$$

The FONC of Eq. (43) is given by:

$\mathrm{E}_{t}\left[\sum_{k=0}^{\infty} \theta^{k} Q_{t, t+k}\left(\tilde{P}_{H, t}-\zeta M C_{t+k}^{n}\right)\left(\frac{\tilde{P}_{H, t}}{P_{H, t+k}}\right)^{-\varepsilon}\left(C_{H, t+k}+C_{H, t+k}^{*}\right)\right]=0$,

which is a familiar expression in studies assuming PCP. Log-linearizing this equality, we have:

$$
\tilde{p}_{H, t}=(1-\beta \theta) \sum_{k=0}^{\infty}(\beta \theta)^{k} \mathrm{E}_{t}\left(m c_{t+k}^{n}\right),
$$

which corresponds to the first equality in Eq. (22). The terms related to the LOOP gap disappear, because the LOOP holds in the PCP model. This equality can be rewritten as follows:

$$
\tilde{p}_{H, t}=p_{H, t-1}+\sum_{k=0}^{\infty}(\beta \theta)^{k} \mathrm{E}_{t}\left(\pi_{H, t+k}\right)+(1-\beta \theta) \sum_{k=0}^{\infty}(\beta \theta)^{k} \mathrm{E}_{t}\left(m c_{t+k}\right),
$$

which corresponds to one derived by Gali and Monacelli [12]. Because of the LOOP, the LOOP gap disappears in Eq. (45), although the LOOP gap appears in the first equality in Eq. (25).

\subsubsection{Marginal Cost and Natural Rate of Output}

Substituting Eq. (9) into the definition of marginal cost, we obtain Eq. (26) and its $\log$-linearized equality Eq. (27). However, the natural rate of output under PCP appears to be quite different from that under LCP. Combining not only Eqs. (14), (18) and Eq. (26) but also $P_{P, t}=P_{H, t}$, we have:

$$
\bar{Y}_{t}=\left[\frac{\zeta^{-1}}{1-\tau} A_{t}^{1+\varphi}\left(\frac{P_{H, t}}{P_{t}}\right)^{-(\sigma \eta-1)}\right]^{\frac{1}{\sigma+\varphi}} D_{t}^{-\frac{\varphi}{\sigma+\varphi}},
$$

which can be log-linearized as follows:

$$
\bar{y}_{t}=\frac{\omega_{1} \omega_{2}}{\omega_{3}} a_{t}-\frac{(\sigma \eta-1) \omega_{2}}{\omega_{3}} a_{t}^{*} .
$$


This equality is consistent with the log-linearized natural rate of output under LCP in Eq. (29), although the natural rate of output is quite different between PCP and LCP before log-linearizing. This implies that differences in pricesetting behavior do not affect the natural rate of output.

The natural rate of output under PCP is consistent with the one under LCP, implying the same relationship between marginal cost and the output gap. In fact, substituting Eqs. (19), (27), (28) and (41) into Eq. (42) yields:

$$
m c_{t}=\frac{\omega_{1}}{2 \eta} x_{t}+\frac{\sigma \eta-1}{2 \eta} x_{t}^{*}
$$

which is consistent with Eq. (30). The difference between the PCP and LCP models is in the price-setting behavior. Because the marginal cost has no relationship with the price-setting behavior, Eq. (30) holds under both PCP and LCP. Note that Gali and Monacelli [12] show that real marginal cost has a relationship only with the domestic output gap, and their result is different from Eq. (30). This difference stems from our two-country setting. As mentioned, foreign output is not exogenous in our setting, and productivity in country $F$ appears in Eq. (29), while foreign output appears in their expression in terms of the percentage deviation from its steady state value. In their setting, foreign output rather than foreign productivity affects the domestic natural rate of output. The foreign output gap no longer affects the domestic output gap, which is determined by the percentage deviation of domestic real marginal cost from its steady state value. Because the percentage deviation of domestic real marginal cost from its steady state value corresponds to its deviation from its flexible price equilibrium value, the foreign output gap disappears in Gali and Monacelli [12]. In fact, we have $m c_{t}=\frac{\omega_{1}}{2 \eta} x_{t}$ if we regard output in country $F$ as exogenous.

\subsubsection{The Demand and Supply Sides}

Substituting Eqs. (21), (23), (41) and (42) into Eq. (10) yields NKIS as follows:

$$
x_{t}=\mathrm{E}_{t}\left(x_{t+1}\right)-\frac{2 \eta}{\sigma_{\alpha}} \hat{r}_{t}+\frac{2 \eta}{\sigma_{\alpha}} \mathrm{E}_{t}\left(\pi_{P, t+1}\right)+\frac{\sigma \eta-1}{\sigma_{\alpha}} \mathrm{E}_{t}\left(\Delta x_{t+1}^{*}\right)+\frac{2 \eta}{\sigma_{\alpha}} \bar{r}_{t},
$$

which is consistent with NKIS under LCP in Eq. (31). While the LOOP does not hold in the LCP model, it holds in the PCP model. Hence, NKISs are not the same in both models, although they are similar. Substituting Eq. (44) into Eq. (46), we have:

$$
x_{t}=\mathrm{E}_{t}\left(x_{t+1}\right)-\frac{2 \eta}{\sigma_{\alpha}} \hat{r}_{t}+\frac{2 \eta}{\sigma_{\alpha}} \mathrm{E}_{t}\left(\pi_{H, t+1}\right)+\frac{\sigma \eta-1}{\sigma_{\alpha}} \mathrm{E}_{t}\left(\Delta x_{t+1}^{*}\right)+\frac{2 \eta}{\sigma_{\alpha}} \bar{r}_{t},
$$

which is applicable only to the PCP model, and $\pi_{H, t}$ replaces $\pi_{P, t}$ in this equality. Because the LOOP holds in the PCP model, changes in neither the expected nominal exchange rate nor the foreign nominal interest rate appear in NKIS under PCP.

By rearranging Eq. (45), we have NKPC in country $H$ under PCP as follows:

$$
\pi_{P, t}=\beta \mathrm{E}_{t}\left(\pi_{P, t+1}\right)+\frac{\lambda \omega_{1}}{2 \eta} x_{t}+\frac{\lambda(\sigma \eta-1)}{2 \eta} x_{t}^{*},
$$


which is the two-country version of NKPC derived by Gali and Monacelli [12]. While the foreign output gap appears in Eq. (47), it does not appear in the NKPC derived by Gali and Monacelli [12], who assume a small open economy where foreign variables are exogenous. Because our model is a two-country model where the foreign variables are endogenous, the foreign output gap appears in our NKPC under PCP. In fact, if we regard output in country $F$ as exogenous, we have:

$$
\pi_{P, t}=\beta \mathrm{E}_{t}\left(\pi_{P, t+1}\right)+\frac{\lambda \omega_{1}}{2 \eta} x_{t},
$$

which is similar to the NKPC derived by Gali and Monacelli [12], and can be derived alternatively if $\sigma \eta=1$ in our two-country model under PCP because the foreign output gap disappears in such a case. Gali and Monacelli [12] show that full stabilization of PPI implies that $x_{t}=\pi_{H, t}=0$, which is plausible if the output gap in country $F$ disappears in Eq. (47). Because of our two-country setting, the foreign output gap does not disappear as long as we do not assume $\sigma \eta=1$. Hence, full stabilization of PPI does not necessarily imply $x_{t}=\pi_{H, t}=0$ in our two-country setting.

\section{Estimation}

In this section, we estimate the LCP and PCP models with an interest rate feedback rule using a Bayesian technique for Japanese and US data.

\subsection{Interest Rate Feedback Rule}

To estimate the LCP and PCP models, both models are closed by the following interest rate feedback rule:

$$
\begin{aligned}
& \hat{r}_{t}=\varrho \hat{r}_{t-1}+(1-\varrho)\left(\phi \pi_{t}+\phi_{x} x_{t}\right)+m_{t}, \\
& \hat{r}_{t}^{*}=\varrho^{*} \hat{r}_{t-1}^{*}+\left(1-\varrho^{*}\right)\left(\phi^{*} \pi_{t}^{*}+\phi_{x}^{*} x_{t}^{*}\right)+m_{t}^{*},
\end{aligned}
$$

where $m_{t}$ and $m_{t}^{*}$ denote policy shifters in countries $H$ and $F$, respectively, and we use monetary policy shifters that follow $\mathrm{AR}(1)$ processes $m_{t}=\rho_{m} m_{t-1}+\zeta_{t}$ and $m_{t}^{*}=\rho_{m}^{*} m_{t-1}^{*}+\zeta_{t}^{*}$ with $\zeta_{t}$ and $\zeta_{t}^{*}$ being i.i.d. shocks.

\subsection{Bayesian Estimation}

There are many methods for estimating DSGE models. Since the seminal paper of Kydland and Prescott [21], many studies have applied calibration methods, in which the parameters are set to be consistent with the model in the steady state. On the other hand, some researchers use the moments of their model to estimate the deep parameters. One of the most popular of these methods is the generalized method of moments (GMM). Furthermore, maximum likelihood (ML) estimation has often been used, e.g., Sargent [30] and Ireland [16]. ML estimation is a full-information analysis, because researchers need not only the information of their model but also that of the stochastic process. Bayesian estimation is also a full-information analysis. Instead of ML estimation, it takes into account information about the parameters known to researchers prior to 
estimation. Recently, most researchers have used Bayesian methods, i.e., Smets and Wouters [31] and Rabanal and Tuesta [29]. In this section, we estimate our models using Bayesian methods.

Following Rabanal and Tuesta [29], we set the discount factor $\beta$ equal to 0.995 so as to be consistent with the nominal rate of interest, two percent per year in the steady state. To estimate the other parameters, we assume their prior distribution as follows. The parameter of relative risk aversion, $\sigma$, the elasticity of substitution between goods produced, $\eta$, the elasticity of labor supply, $\varphi$, the reaction coefficients to CPI inflation, $\phi$ and $\phi^{*}$, and the reaction coefficients to the output gap, $\phi_{x}$ and $\phi_{x}^{*}$, are all assumed to follow a normal distribution. The parameter of price stickiness, $\theta$, the interest rate inertia parameter in the interest rate feedback rules, $\varrho$ and $\varrho^{*}$, and the coefficients of the $\operatorname{AR}(1)$ processes, $\rho, \rho^{*}, \rho_{m}$, and $\rho_{m}^{*}$, are all assumed to be distributed as a beta distribution. The standard deviations of $\xi, \xi^{*}, \zeta$ and $\zeta^{*}$ are assumed to follow an inverse gamma distribution. For the parameter of the first prior, we follow Obstfeld and Rogoff's [28] estimation results, we follow Benigno and Benigno's [2] setting based on Obstfeld and Rogoff's [28] estimation results for the parameter of the second prior and we follow Gali and Monacelli's [12] setting or Smets and Wouters' [31] setting for the others. These assumptions are shown in Table 1.

We estimate the parameters using a Markov-chain Monte Carlo (MCMC) method with these priors. The likelihood function of the observed data series is evaluated by a Kalman filter. The posterior distribution of the parameters is obtained through the Metropolis-Hastings algorithm. For the posterior distribution, 200,000 draws are created using the Metropolis-Hastings algorithm, and the first half of these draws is discarded.

\subsection{Data}

We estimate our models using Japan as country $H$ and the United States as country $F$. The data on real GDP, interest rates on government bonds, and the CPI are from International Financial Statistics provided by the IMF. We use quarterly observations for the period 1980:Q1 to 2008:Q4. The data on the labor force are from the OECD Economic Outlook database.

To obtain the real per capita GDP gap series, we divide real GDP by the labor force and apply the HP filter. As suggested by Hodrick and Prescott [14] for quarterly data, we set the smoothing parameter to be 1600 . We divide the annual interest rate by four to get the quarterly interest rate. The first difference of the logarithmic CPI is used as the CPI inflation rate. All series, except for interest rates, are seasonally adjusted using X12-ARIMA.

\subsection{Results}

Table 2 reports the posterior means and $90 \%$ credible intervals for the parameters in both the LCP and PCP models. The mean of the relative risk aversion parameter $\sigma$ is estimated to be 4.440 in the LCP model and 2.518 in the PCP model, respectively (the third row in Table 2). The value of $\sigma$ in the PCP model is similar to some studies, such as 2.045 in Levin et al. [22] and 2.041 in Iiboshi et al. [15]. The estimates of the parameter for the inverse of the labor supply elasticity $\varphi$ are 2.389 in the LCP model and 5.737 in the PCP model (the fifth row in Table 2). The estimate of $\varphi$ in the LCP model is close to those in Smets 
and Wouters [31], Iiboshi et al. [15] and Sugo and Ueda [32], who estimate this parameter within the range 2.149 to 2.503 . $\eta$ is estimated to be 4.526 in the LCP model and 8.174 in the PCP model (the fourth row in Table 2). The estimate of $\eta$ in the LCP model is close to Obstfeld and Rogoff [28], who estimate it to be 4.5. The price-stickiness parameter $\theta$ is estimated to be 0.910 in the LCP model and 0.909 in the PCP model. The estimates of the price-stickiness parameter are close to the 0.875 for Japan reported in Sugo and Ueda[32] and the 0.873 for the US in Adjemian et al. [1]. Therefore, our estimated results for $\theta$ are plausible.

Regarding interest rate feedback rules, the coefficients of the inflation rate in country $H \phi$ are 1.264 in the LCP Model and 1.582 in the PCP Model (the ninth row in Table 2). These results are similar to those in some Japanese studies that estimate interest rate feedback rules such as Kimura and Tanemura [20], Kamada and Muto [18] and Fujiwara et al. [10], who estimate the value to range from 1.33 to 1.60 using Japanese data. For $F \phi^{*}$, the coefficients of the inflation rate are estimated as 1.673 in the LCP model and 1.574 in the PCP model (the 10th row in Table 2). These results are close to the results of Mehra and Sawhney [24], who estimate the coefficients of the inflation rate to be 1.5 in the US. The coefficients of the output gap in country $H \phi_{x}$ are 0.257 in the LCP model and 0.212 in the PCP model, which are larger than those in Sugo and Ueda [32], who report this coefficient to be 0.11 (the 11th row in Table 2). In country $F, \phi_{x}^{*}$ is 0.087 in the LCP model and 0.170 in the PCP model, which are larger than those in some studies for the US such as Smets and Wouters [31] and Levin et al. [22] (the 12th row in Table 2). The results for interest rate inertia in country $H \varrho$ are 0.647 in the LCP model and 0.321 in the PCP model, which are less than those reported in Sugo and Ueda [32], who estimate the inertia parameter to be 0.842 in Japan (the seventh row in Table 2 ). The interest rate inertia parameter in country $F \varrho^{*}$ is 0.539 in the LCP model and 0.339 in the PCP model, which are smaller than those of the US, which are 0.956 in Smets and Wouters [31] and 0.832 in Levin et al. [22] (the eighth row in Table 2). The coefficients of the AR(1) processes for productivity $\rho$ and $\rho^{*}$ are estimated to be between 0.440 and 0.735 in the LCP and PCP models, respectively (the 13th and 14th rows in Table 2). These results do not contradict the result in Gali and Monacelli [12], who report an AR(1) coefficient for productivity of 0.66 .

Some estimation results are similar between the PCP model and the LCP model. However, three deep parameters, $\sigma, \varphi$ and $\eta$, are obviously different between the two models. While the result of $\sigma$ in the PCP model is similar to that of previous studies, the results for the other two deep parameters $\varphi$ and $\eta$ in the LCP model are close to previous studies. Incidentally, in the LCP model, the $\operatorname{AR}(1)$ coefficient of productivity in country $H \rho$ and that in country $F$ $\rho^{*}$ are similar to the results shown in Gali and Monacelli [12]. Furthermore, because the interest rate inertia parameters $\varrho$ and $\varrho^{*}$ of the LCP model are larger than those of the PCP model, it can be said that the estimates of $\varrho$ and $\varrho^{*}$ in the LCP model, but not in the PCP model, somewhat reflect the results of Sugo and Ueda [32], who mention that monetary policy has significant inertia. The LCP model may be plausible from the viewpoint of the estimation results. We further discuss whether the LCP or PCP models are plausible in the next subsection. 


\subsection{Model Comparison}

In the previous section, we estimated the LCP and PCP models. Next, we formally compare these models using Bayes factors. Denoting $M_{L C P}$ and $M_{P C P}$ as the LCP and PCP models, respectively, and $D$ as the data, the posterior odds ratio for $M_{L C P}$ against $M_{P C P}$ is:

$$
\frac{P\left(M_{L C P} \mid D\right)}{P\left(M_{P C P} \mid D\right)}=\frac{P\left(M_{L C P}\right)}{P\left(M_{P C P}\right)} \frac{P\left(D \mid M_{L C P}\right)}{P\left(D \mid M_{P C P}\right)} .
$$

The second term on the right-hand side of this equation is called the Bayes factor. As we do not have any information on which model is plausible, we set the priors $P\left(M_{L C P}\right)$ and $P\left(M_{P C P}\right)$ equal to 0.5 . In this case, the first term on the right-hand side is unity, so that the posterior odds ratio is equal to the Bayes factor.

Following Kass and Raftery [19], we use three indices: the Bayes factor $B$, $2 \ln B$ and $\log _{10} B$. Kass and Raftery [19] suggest that according to their values, $B$ and $2 \ln B$ are considered to be (i) not worth more than a bare mention, (ii) positive, (iii) strong, and (iv) very strong. Furthermore, the criteria of Jeffreys [17] are (i) not worth more than a bare mention, (ii) substantial, (iii) strong, and (iv) decisive. We estimate the marginal likelihood using the Laplace approximation and the modified harmonic mean.

The estimated Bayes factors are shown in Table 5, all of which have large values. It suggests that the evidence in favor of $M_{L C P}$ is "very strong" $(B>$ 150). The results of $2 \ln B$ are also the same as those for $B$, that is, $2 \ln B$ of greater than 10 means "very strong." Furthermore, the values of $\log _{10} B$ being greater than two are interpreted as "decisive." Therefore, the LCP model is strongly supported against the PCP model from the data, and this finding is consistent with Engel and Rogers [7], Goldberg and Knetter [13] and Frankel, Parseley and Wei [9], who show that the LCP model is dominant.

\section{Optimal Monetary Policy under LCP and PCP}

In this section, we discuss the properties of optimal monetary policy in the LCP and PCP models. We derive microfounded period loss functions to obtain optimality conditions for the central banks. We simulate the LCP and the PCP models with optimality conditions, which replace the interest rate feedback rule, to obtain impulse response functions, and discuss the properties of optimal monetary policy in the LCP and PCP models.

\subsection{Welfare Costs}

We assume that each country has a central bank, and that these central banks conduct optimal monetary policy. Central banks minimize welfare costs. Welfare costs consist of the period loss function, which is derived from the welfare criteria. Following Woodford [34] and Gali [11], we have a second-order approximated utility function as follows:

$\mathcal{W}_{L C P}^{W}=-\mathcal{L}_{L C P}^{W}+$ t.i.p. $+o\left(\|\xi\|^{3}\right) ; \mathcal{W}_{P C P}^{W}=-\mathcal{L}_{P C P}^{W}+$ t.i.p. $+o\left(\|\xi\|^{3}\right),(50$

where $\mathcal{L}_{L C P}^{W} \equiv \mathrm{E}_{0} \sum_{t=0}^{\infty} \beta^{t} L_{L C P, t}^{W}$ and $\mathcal{L}_{P C P}^{W} \equiv \mathrm{E}_{0} \sum_{t=0}^{\infty} \beta^{t} L_{P C P, t}^{W}$ denote the loss function in LCP and PCP models, respectively, $\mathcal{W}_{L C P}^{W}=\frac{1}{2}\left(\mathcal{W}_{L C P}+\mathcal{W}_{L C P}^{*}\right)$ 
and $\mathcal{W}_{P C P}^{W}=\frac{1}{2}\left(\mathcal{W}_{P C P}+\mathcal{W}_{P C P}^{*}\right)$ denote the average welfare criteria in the LCP and PCP models, respectively, $W_{L C P}^{W}$ and $W_{P C P}^{W}$ denote the welfare criteria in country $H$ in the LCP and PCP models, respectively, with $\mathcal{W} \equiv \sum_{t=0}^{\infty} \mathrm{E}_{0}\left(\mathcal{W}_{t}\right)$ and $\mathcal{W}_{t} \equiv \frac{U_{t}-U}{U_{C} C}$. Furthermore:

$$
\begin{aligned}
L_{L C P, t}^{W} & \equiv \frac{1}{2}\left[\frac{\varepsilon}{2 \lambda} \pi_{t}^{2}+\frac{\varepsilon}{2 \lambda}\left(\pi_{t}^{*}\right)^{2}+(\sigma+\varphi)\left(x_{t}^{W}\right)^{2}+\frac{(1+\varphi) \eta^{2}}{4} z_{t}^{2}\right] \\
L_{P C P}^{W} & \equiv \frac{1}{2}\left[\frac{\varepsilon}{2 \lambda} \pi_{P, t}^{2}+\frac{\varepsilon}{2 \lambda}\left(\pi_{P, t}^{*}\right)^{2}+(\sigma+\varphi)\left(x_{t}^{W}\right)^{2}+\frac{(1+\varphi) \eta^{2}}{4} z_{t}^{2}\right]
\end{aligned}
$$

are period loss functions in countries $H$ and $F$, respectively, $z_{t} \equiv s_{t}-\bar{s}_{t}$ being the deviation of the TOT from its efficient level, $\bar{s}_{t} \equiv \frac{1+\varphi \eta}{\eta^{2}(1+\varphi)} \bar{y}_{t}^{R}$ being the efficient level of TOT. Note that we define $v_{t}^{W} \equiv \frac{1}{2}\left(v_{t}+v_{t}^{*}\right)$ and $v_{t}^{R} \equiv v_{t}-v_{t}^{*}$.

Eqs. (51) and (52) imply that the role of central banks is minimizing fluctuations in the deviation of the TOT from its efficient level $z_{t}$ and the average output gap $x_{t}^{W}$ in the LCP and PCP models. On stabilizing inflation, the role of central banks is different between the LCP and PCP models. The quadratic terms of the CPI inflation rate appears and replaces the quadratic terms of PPI inflation in our loss function under LCP in Eq. (51), although the quadratic terms of PPI inflation appear in our loss function under PCP in Eq. (52), as in Gali and Monacelli [12] and Benigno and Benigno [2]. These facts imply that the role of central banks is minimizing fluctuations in the LCP model, while in the PCP model their role is minimizing fluctuations in PPI inflation.

\subsection{FONCs for Central Banks}

We next briefly discuss the FONCs for the central banks. We assume that the central bank in each country conducts cooperatively optimal monetary policy with commitment. Under LCP, central banks minimize Eq. (51) and the FONCs for them are given by:

$$
\begin{aligned}
\pi_{t}^{W} & =-\frac{1}{\varepsilon}\left(x_{t}^{W}-x_{t-1}^{W}\right) \\
z_{t} & =0 .
\end{aligned}
$$

Because of commitment, lagged variables appear in the FONCs. Eqs. (53) and (54) determine the equilibrium path of the output gap, CPI inflation and the deviations of the TOT from its efficient level in the LCP model along with the structural model. Eq. (53) implies that there are no tradeoffs between the output gap and inflation in an economy consisting of two countries under optimal monetary policy. This implication is consistent with the outcome under the assumption of a closed economy. Eq. (54) implies that full stabilization of the deviation in the TOT from its efficient level is optimal regardless of preferences such as the elasticity of substitution between goods produced in countries $H$ and $F \eta$ and the relative risk aversion $\sigma$.

Under PCP, central banks minimize Eq. (52), and the FONCs for them are given by:

$$
\begin{array}{r}
\pi_{t}^{W}=-\frac{1}{\varepsilon}\left(x_{t}^{W}-x_{t-1}^{W}\right), \\
\pi_{P, t}^{R}=-\frac{(1+\varphi) \eta^{2}}{\varepsilon(1+\eta \varphi)}\left(z_{t}-z_{t-1}\right) .
\end{array}
$$


One of the FONCs is consistent with Eq. (53), and Eqs. (53) and (55) determine the equilibrium path of the output gap, PPI inflation and the deviation of the TOT from its efficient level in the PCP model along with the structural model. Because one of the FONCs is consistent with Eq. (53), there are no tradeoffs between the output gap and inflation in the economy that consists of two countries under optimal monetary policy. Eq. (55) does not show clear implications of the tradeoffs between the output gap and inflation. However, under the special case, the implications of Eq. (55) are clear. By substituting $\eta=1$ into Eq. (55), we have:

$$
\pi_{P, t}^{R}=-\frac{1}{\varepsilon}\left(x_{t}^{R}-x_{t-1}^{R}\right)
$$

which implies that inflation-output-gap tradeoffs are fully dissolved in each country under optimal monetary policy when the elasticity of substitution between goods produced in countries $H$ and $F$ is unity.

\subsection{Simulation}

In this section, we simulate optimal monetary policy in the LCP and PCP models. The optimality conditions for the central banks, Eqs. (53), (54) and (55), replace the interest rate feedback rules Eqs. (48) and (49) in the LCP and PCP models. Figure 1 shows the impulse responses to a one-standard-deviation increase in the productivity shock in country $H, \xi_{t}$, in the LCP model under the parameters estimated in Section 3.4. Figure 2 shows those in the PCP model. Note that the elasticity of substitution across goods $\varepsilon$ is calibrated to 11 following Ferrero's [8] calibrated parameter value, because the elasticity of substitution across goods only appears in the optimality condition and cannot be estimated because this elasticity does not appear in the estimated LCP and PCP models. Figures 1 and 2 depict posterior means (solid lines) and pointwise $90 \%$ posterior probability intervals (dotted lines) for the impulse responses to one-standard-deviation shocks in the percentage deviation from the steady state. Macroeconomic volatilities that are evaluated at the posterior mean parameters are shown in Table $4 .^{11}$

Under PCP, the PPI inflation rate in countries $H$ and $F$ is more stabilized than the CPI inflation rate in countries $H$ and $F$ (panels 3 to 6 in Figure 2 ). This result is consistent with Gali and Monacelli [12], who imply that PPI inflation targeting produces a zero output gap. This result can be understood by paying attention to Eq. (47). Although this setting does not correspond to our estimation result, we have NKPC in the PCP model under a special case by substituting $\sigma=\eta=1$ into Eq. (47) as follows:

$$
\pi_{P, t}=\beta \mathrm{E}_{t}\left(\pi_{P, t+1}\right)+\frac{\lambda \omega_{1}}{2 \eta} x_{t} .
$$

This NKPC implies that stabilizing PPI inflation stabilizes the output gap simultaneously, and is consistent with the one derived by Gali and Monacelli [12], although the slope of our NKPC is slightly different from theirs because

\footnotetext{
${ }^{11}$ As shown in the optimality conditions in Eqs. (53), (54) and (55), the LCP and PCP models are not affected by $\zeta_{t}$ and $\zeta_{t}^{*}$. Only $\xi_{t}$ and $\xi_{t}^{*}$ affect the LCP and PCP models under optimal monetary policy.
} 
we assume a two-country economy. Because the special case $\sigma=\eta=1$ does not correspond to our posterior result, the PPI inflation rate is not completely stabilized and fluctuates slightly, and the volatilities in the PPI inflation rate in countries $H$ and $F$ are 3.65E-05 and 2.01E-05 to changes in productivity in countries $H$ and $F$, respectively (the seventh and eighth rows in Table 4). ${ }^{12}$ Needless to say, the nominal exchange rate fluctuates in the PCP model (the 17th row in Table 4 and panel 13 in Figure 2). This fact implies that a flexible exchange rate regime is the optimal regime under $\mathrm{PCP}$.

Under LCP, CPI inflation rather than PPI inflation is completely stabilized, and this result is different from Gali and Monacelli [12] (the ninth and 10th rows in Table 4 and panels 3 and 4 in Figure 1). This can be understood by examining Eq. (35), which can be rewritten as:

$$
\pi_{t}=\beta \mathrm{E}_{t}\left(\pi_{t+1}\right)+\kappa_{\alpha} x_{t}^{W} .
$$

This equality implies that CPI inflation is zero when the average output gap is stabilized. In fact, the volatility of the average output gap $x_{t}^{W}$ is zero, as shown in the third row in Table 4 . In addition, the fifth and sixth rows in Table 4 and panels 1 and 2 in Figure 1 show that volatilities and fluctuations in the output gap in countries $H$ and $F$ are symmetric. This suggests that the average output gap is zero because $x_{t}^{W}=\frac{1}{2}\left(x_{t}+x_{t}^{*}\right)$. Interestingly, the nominal exchange rate is completely stabilized under LCP, as shown in the 17th row in Table 4 and the 13th panel in Figure 1. As mentioned in Section 2.1.3, PPP always holds, even if LCP is assumed. Hence, $e_{t}+p_{t}^{*}=p_{t}$ holds. Perfect stabilization in CPI inflation implies $p_{t}=p_{t}^{*}=0$, which is consistent with $e_{t}=0$. Thus, under LCP, there are neither changes in CPI inflation nor in the nominal exchange rate. This is consistent with Devereux and Engel [5], who develop an NOEM model assuming LCP and showing that a fixed exchange rate is an optimal regime from the viewpoint of maximizing welfare. Our result that there are no fluctuations in the nominal exchange rate stems from stabilizing the CPI inflation rate. Perfect stabilization in CPI inflation is consistent with perfect stabilization in the CPI level. ${ }^{13}$ Thus, it can be said that our result is consistent with Corsetti, Dedola and Leduc [3], who show that CPI stabilization is optimal. We now reconcile Devereux and Engel's [5] main finding with Corsetti, Dedola and Leduc's [3] main finding, although Corsetti, Dedola and Leduc [3] point out that there is a strong tradeoff in stabilization between the nominal exchange rate and the CPI. Perfect stabilization in CPI inflation is not inconsistent with perfect stabilization in the nominal exchange rate.

\section{Conclusion}

We analyzed optimal monetary policy in an LCP model by comparing it with a PCP model, and produced two main findings, as follows. Optimal monetary

\footnotetext{
${ }^{12}$ In the special case, balanced trade is attained and the foreign output gap does not affect domestic inflation under PCP. However, in the general case $\sigma<1$ and $\eta \neq 1$, which is consistent with our estimation result, the foreign output gap affects domestic inflation, as shown in Eq. (47). Hence, a tradeoff between PPI inflation and the output gap cannot be completely dissolved even if optimal monetary policy is conducted. See Benigno and Benigno [2] for details.

${ }^{13}$ We assume a zero inflation deterministic steady state.
} 
policy under LCP produces no fluctuations in the CPI inflation rate. Roughly speaking, optimal monetary policy under LCP is CPI inflation targeting. This result is quite different from the result in Gali and Monacelli [12] who show that stabilizing in the PPI inflation is optimal. We also showed that there are no fluctuations in the nominal exchange rate under LCP. Roughly speaking, optimal monetary policy under LCP is consistent with a fixed exchange rate regime, as showed by Devereux and Engel [5]. We reconciled our results with Devereux and Engel [5], and derived policy implications that were consistent with Woodford's [33] motivation.

Our policy implication for LCP is important, because our estimation results based on Japanese and US data strongly support the LCP model. Regarding our empirical and theoretical results, it can be said that central banks, not only in Japan and the US, but also in other countries where LCP is dominant, should pursue monetary policy that stabilizes the CPI inflation rate from the viewpoint of minimizing welfare costs.

Our finding sheds light on Mussa's puzzle, which focuses on the comovement of the nominal exchange rate and real exchange rate, as in Betts and Devereux [4]. Because complete stabilization in the CPI inflation rate coincides with complete stabilization in the nominal exchange rate under LCP, one of the answers to Mussa's puzzle may be optimal monetary policy under LCP. Solving Mussa's puzzle along with the result in this paper remains an objective for future research.

\section{References}

[1] Adjemian, Stephane, Matthieu Darracq-Paries and Frank Smets (2008), "A Quantitative Perspective on Optimal Monetary Policy Cooperation between the US and the Euro Area," ECB Working Paper, No. 884.

[2] Benigno, Pierpaolo and Gianluca Benigno (2006), "Designing Targeting Rules for International Monetary Policy Cooperation," Journal of Monetary Economics, 53, 473-506.

[3] Corsetti, Giancarlo, Luca Dedola and Sylvain Leduc (2007), "Optimal Monetary Policy and the Sources of Local-Currency Price Stability," in International Dimensions of Monetary Policy, University of Chicago Press, Chicago, IL.

[4] Betts, Caroline and Michael B. Devereux (2000), "Exchange Rate Dynamics in a Model of Pricing-to-market," Journal of International Economics, 50, 215-244.

[5] Devereux, Michael B. and Charles Engel (2003), "Monetary Policy in the Open Economy Revisited: Price Setting and Exchange Rate Flexibility," Review of Economic Studies, 70, 765-84.

[6] Devereux, Michael B., Philip R. Lane and Juanyi Xu (2006), "Exchange Rates and Monetary Policy in Emerging Market Economies," Economic Journal, 116, 478-506. 
[7] Engel, Charles and John H. Rogers (1996), "How Wide Is the Border?," American Economic Review, 86, 1112-1125.

[8] Ferrero, Andrea (2009), "Fiscal and Monetary Rules for a Currency Union," Journal of International Economics, 77, 1-10.

[9] Frankel, Jeffrey, David Parseley and Shang-Jin Wei (2004), "Slow Passthrough around the World: A New Import for Developing Countries?," mimeo, Harvard University.

[10] Fujiwara, Ippei, Naoko Hara, Naohisa Hirakata, Takeshi Kimura and Shinichiro Watanabe (2007), "Japanese Monetary Policy During the Collapse of the Bubble Economy," Monetary and Economic Studies, 25, 89-128.

[11] Gali, Jordi (2008), "Monetary Policy, Inflation and the Business Cycle," Princeton University Press, Princeton, NJ.

[12] Gali, Jordi and Tommaso Monacelli (2005), "Monetary Policy and Exchange Rate Volatility in a Small Open Economy," Review of Economic Studies, 72, 707-734.

[13] Goldberg, Pinelopi K. and Michael M. Knetter (1997), "Goods Prices and Exchange Rates: What have we Learned?," Journal of Economic Literature, $35,1243-1272$.

[14] Hodrick, Robert J. and Edward C. Prescott (1997), "Post-war U.S. Business Cycles: An Empirical Investigation," Journal of Money, Credit and Banking, 29, 1-16.

[15] Iiboshi, Hirokuni, Shin-Ichi Nishiyama and Toshiaki Watanabe (2006), "An Estimated Dynamic Stochastic General Equilibrium Model of the Japanese Economy: A Bayesian Analysis," mimeo.

[16] Ireland, Peter N. (2004), "A Method for Taking Models to the Data," Journal of Economic Dynamics and Control, 28, 1205-1226.

[17] Jeffreys, Harold (1961), "Theory of Probability (Third Edition)," Oxford University Press, Oxford, UK.

[18] Kamada, Koichiro and Ichiro Muto (2000), "Analysis of Japanese Financial Policies Using Forward-Looking Models [Fuowa-do Rukkingu Moderu ni Yoru Wagakuni Kinyu Seisaku no Bunseki]," Monetary and Economic Studies [Kin'yu Kenkyu], 19, 103-144 (in Japanese).

[19] Kass, Robert E. and Adrian E. Raftery (1995), "Bayes Factors," Journal of the American Statistical Association, 90, No. 430, 773-795.

[20] Kimura, Takeji and Tomoki Tanemura (2000), "Financial Policy Rules and Macroeconomic Stability [Kinyu Seisaku Ru-ru to Makuro Keizai no Anteisei]," Monetary and Economic Studies [Kin'yu Kenkyu], 19, 101-159 (in Japanese).

[21] Kydland, Finn, and Edward Prescott (1982), "Time to Build and Aggregate Fluctuations," Econometrica, 50, 1345-1370. 
[22] Levin, Andrew T., Alexei Onatski, John Williams and Noah M. Williams (2005), "Monetary Policy under Uncertainty in Micro-Founded Macroeconometric Models," In: NBER Macroeconomics Annual, 20, 229-287.

[23] Mark, Nelson (2001), "International Macroeconomics and Finance," Blackwell, Oxford, UK.

[24] Mehra, Yash P. and Bansi Sawhney (2010), "Inflation Measure, Taylor Rules, and the Greenspan-Bernanke Years," Economic Quarterly, 96, 123151.

[25] Monacelli, Tommasso (2005), "Monetary Policy in a Low Pass-Through Environment," Journal of Money, Credit and Banking, 37, 1047-1066.

[26] Obstfeld, Maurice and Kenneth Rogoff (1995), "Exchange Rate Dynamics Redux," Journal of Political Economy 103, 624-660.

[27] Obstfeld, Maurice and Kenneth Rogoff (2000a), "New Directions for Stochastic Open Economy Models," Journal of International Economics 50, $117-153$.

[28] Obstfeld, Maurice, and Kenneth Rogoff (2000b), "The Six Major Puzzles in International Finance: Is There a Common Cause?," In: NBER Macroeconomics Annual, 15.

[29] Rabanal, Pau and Vicente Tuesta (2006), "Euro-Dollar Real Exchange Rate Dynamics in an Estimated Two-Country Model: What is Important and What is Not," CEPR Discussion Paper, No. 5957.

[30] Sargent, Thomas (1989), "Two Models of Measurements and the Investment Accelerator," Journal of Political Economy, 97, 251-287.

[31] Smets, Frank and Rafael Wouters (2003), "An Estimated Dynamic Stochastic General Equilibrium Model of the Euro Area," Journal of the European Economic Association, 1, 1123-1175.

[32] Sugo, Tomohiro and Kozo Ueda (2008), "Estimating a Dynamic Stochastic General Equilibrium Model for Japan," Journal of the Japanese and International Economies, 22, 476-502.

[33] Woodford, Michael (2001), "Inflation Stabilization and Welfare," NBER Working Paper, No. 8071.

[34] Woodford, Michael (2003), "Interest and Prices," Princeton University Press, Princeton, NJ. 
Table 1: Prior distributions of parameters

\begin{tabular}{c|crr}
\hline \hline Parameter & Distribution & Mean & S.D. \\
\hline$\sigma$ & Normal & 3 & 1 \\
$\eta$ & Normal & 4.5 & 1 \\
$\varphi$ & Normal & 3 & 1 \\
$\theta$ & Beta & 0.75 & 0.05 \\
$\varrho$ & Beta & 0.8 & 0.1 \\
$\varrho^{*}$ & Beta & 0.8 & 0.1 \\
$\phi$ & Normal & 1.7 & 0.1 \\
$\phi^{*}$ & Normal & 1.7 & 0.1 \\
$\phi_{x}$ & Normal & 0.125 & 0.05 \\
$\phi_{x}^{*}$ & Normal & 0.125 & 0.05 \\
$\rho$ & Beta & 0.85 & 0.1 \\
$\rho^{*}$ & Beta & 0.85 & 0.1 \\
$\rho_{m}$ & Beta & 0.85 & 0.1 \\
$\rho_{m}^{*}$ & Beta & 0.85 & 0.1 \\
$\sigma_{\xi}$ & Inv. Gamma & 0.4 & 2 \\
$\sigma_{\xi}^{*}$ & Inv. Gamma & 0.4 & 2 \\
$\sigma_{\zeta}$ & Inv. Gamma & 0.1 & 2 \\
$\sigma_{\zeta}^{*}$ & Inv. Gamma & 0.1 & 2 \\
\hline
\end{tabular}


Table 2: Posterior distributions of parameters

\begin{tabular}{c|cccc}
\hline \hline & \multicolumn{2}{|c}{ LCP model } & \multicolumn{2}{c}{ PCP Model } \\
\cline { 2 - 5 } Parameter & Mean & $90 \%$ Interval & Mean & $90 \%$ Interval \\
\hline$\sigma$ & 4.440 & {$[3.159,5.688]$} & 2.518 & {$[1.759,3.260]$} \\
$\eta$ & 4.526 & {$[2.923,6.148]$} & 8.174 & {$[6.939,9.485]$} \\
$\varphi$ & 2.389 & {$[0.820,3.875]$} & 5.737 & {$[4.525,6.941]$} \\
$\theta$ & 0.910 & {$[0.888,0.931]$} & 0.909 & {$[0.891,0.926]$} \\
$\varrho$ & 0.647 & {$[0.523,0.775]$} & 0.321 & {$[0.209,0.430]$} \\
$\varrho^{*}$ & 0.539 & {$[0.406,0.658]$} & 0.339 & {$[0.238,0.440]$} \\
$\phi$ & 1.264 & {$[1.064,1.410]$} & 1.582 & {$[1.409,1.760]$} \\
$\phi^{*}$ & 1.673 & {$[1.507,1.823]$} & 1.574 & {$[1.396,1.750]$} \\
$\phi_{x}$ & 0.257 & {$[0.189,0.323]$} & 0.212 & {$[0.138,0.284]$} \\
$\phi_{x}^{*}$ & 0.087 & {$[0.041,0.135]$} & 0.170 & {$[0.097,0.241]$} \\
$\rho$ & 0.714 & {$[0.556,0.888]$} & 0.440 & {$[0.358,0.528]$} \\
$\rho^{*}$ & 0.662 & {$[0.581,0.741]$} & 0.735 & {$[0.674,0.794]$} \\
$\rho_{m}$ & 0.845 & {$[0.748,0.956]$} & 0.994 & {$[0.989,1.000]$} \\
$\rho_{m}^{*}$ & 0.998 & {$[0.996,0.999]$} & 0.993 & {$[0.988,0.999]$} \\
$\sigma_{\xi}$ & 0.352 & {$[0.091,0.681]$} & 1.264 & {$[1.083,1.456]$} \\
$\sigma_{\xi}^{*}$ & 4.719 & {$[1.568,7.985]$} & 0.687 & {$[0.541,0.843]$} \\
$\sigma_{\zeta}$ & 0.069 & {$[0.041,0.095]$} & 0.214 & {$[0.139,0.289]$} \\
$\sigma_{\zeta}^{*}$ & 0.201 & {$[0.135,0.271]$} & 0.213 & {$[0.139,0.286]$} \\
\hline
\end{tabular}

Table 3: Model comparison with Bayes factors

\begin{tabular}{c|cc}
\hline \hline Index & Laplace approximation & Modified harmonic mean \\
\hline $\ln P\left(D \mid M_{L C P}\right)$ & -556.80 & -556.98 \\
$\ln P\left(D \mid M_{P C P}\right)$ & -575.65 & -575.13 \\
$B$ & $1.52 \times 10^{8}$ & $7.63 \times 10^{7}$ \\
$2 \ln (B)$ & 37.68 & 36.30 \\
$\log _{10}(B)$ & 8.18 & 7.88 \\
\hline
\end{tabular}


Table 4: Macroeconomic volatility to a one-s.d. increase in productivity

\begin{tabular}{c|ccrr}
\hline \hline & \multicolumn{2}{|c}{ LCP model } & \multicolumn{2}{c}{ PCP model } \\
\hline Shocks & $\xi_{t}$ & $\xi_{t}^{*}$ & \multicolumn{1}{c}{$\xi_{t}$} & $\xi_{t}^{*}$ \\
\hline$x_{t}^{W}$ & 0.00000 & 0.00000 & 0.00000 & 0.00000 \\
$\pi_{t}^{W}$ & 0.00000 & 0.00000 & 0.00000 & 0.00000 \\
$x_{t}$ & 0.00091 & 0.01340 & 0.00066 & 0.00036 \\
$x_{t}^{*}$ & 0.00091 & 0.01340 & 0.00066 & 0.00036 \\
$\pi_{P, t}$ & 0.00045 & 0.00586 & $3.65 \mathrm{E}-05$ & $2.01 \mathrm{E}-05$ \\
$\pi_{P, t}^{*}$ & 0.00045 & 0.00586 & $3.65 \mathrm{E}-05$ & $2.01 \mathrm{E}-05$ \\
$\pi_{t}$ & 0.00000 & 0.00000 & 0.00092 & 0.00050 \\
$\pi_{t}^{*}$ & 0.00000 & 0.00000 & 0.00092 & 0.00050 \\
$\hat{r}_{t}$ & 0.00162 & 0.02177 & 0.00833 & 0.00200 \\
$\hat{r}_{t}^{*}$ & 0.00162 & 0.02177 & 0.00753 & 0.00217 \\
$y_{t}$ & 0.00399 & 0.01604 & 0.01326 & 0.00097 \\
$y_{t}^{*}$ & 0.00131 & 0.04604 & 0.00176 & 0.00725 \\
$s_{t}$ & 0.00121 & 0.01435 & 0.00185 & 0.00101 \\
$z_{t}$ & 0.00000 & 0.00000 & 0.00013 & $6.89 \mathrm{E}-05$ \\
$e_{t}$ & 0.00000 & 0.00000 & 0.00175 & 0.00096 \\
\hline \multicolumn{2}{r}{}
\end{tabular}


Figure 1: IRFs to productivity shocks in country $H$ in the LCP model
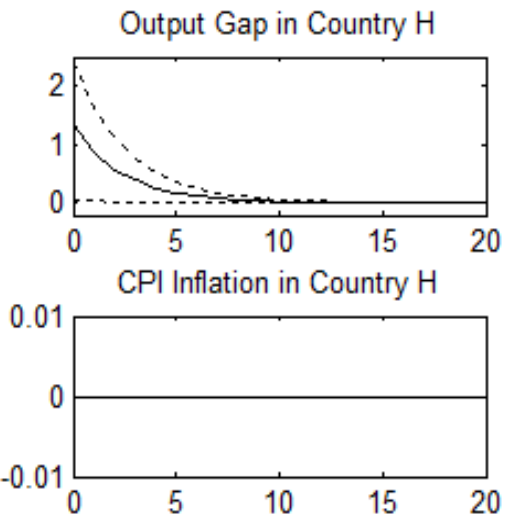

PPI Inflation in Country $\mathrm{H}$
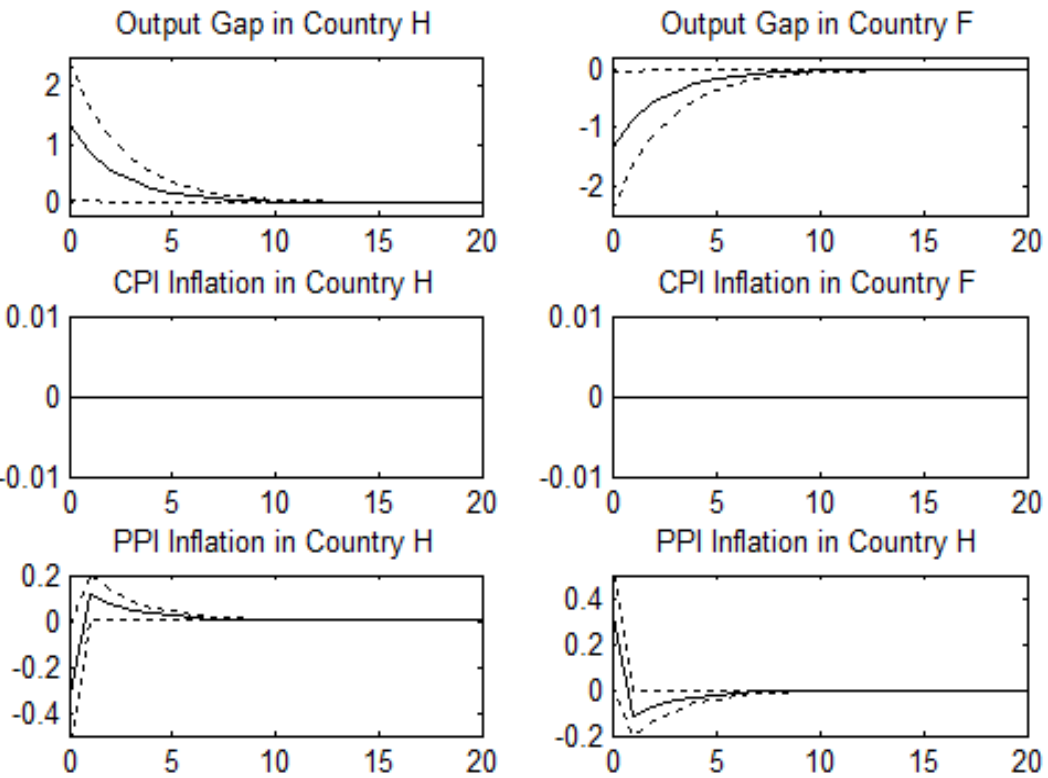

Nominal Interest Rate in Country $\mathrm{H}$
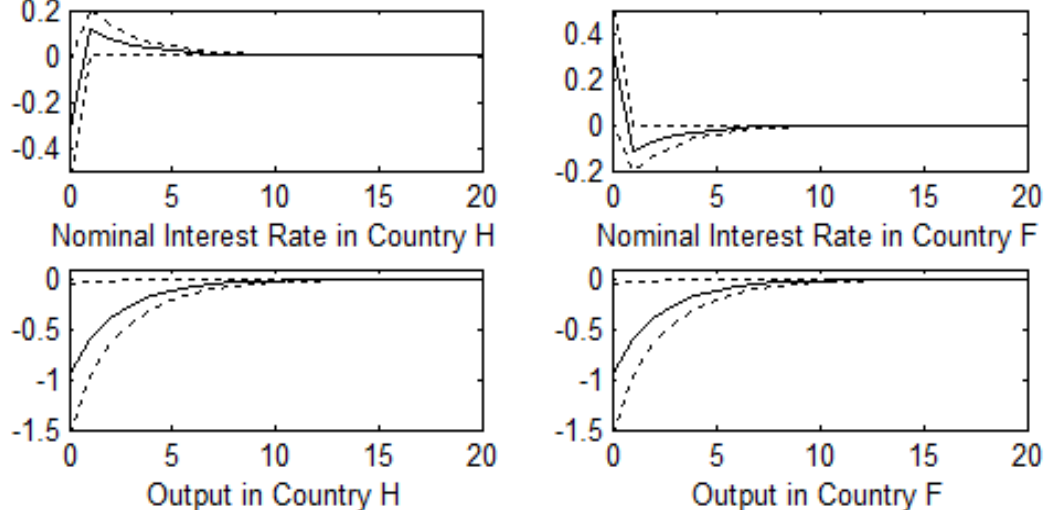

Nominal Interest Rate in Country F
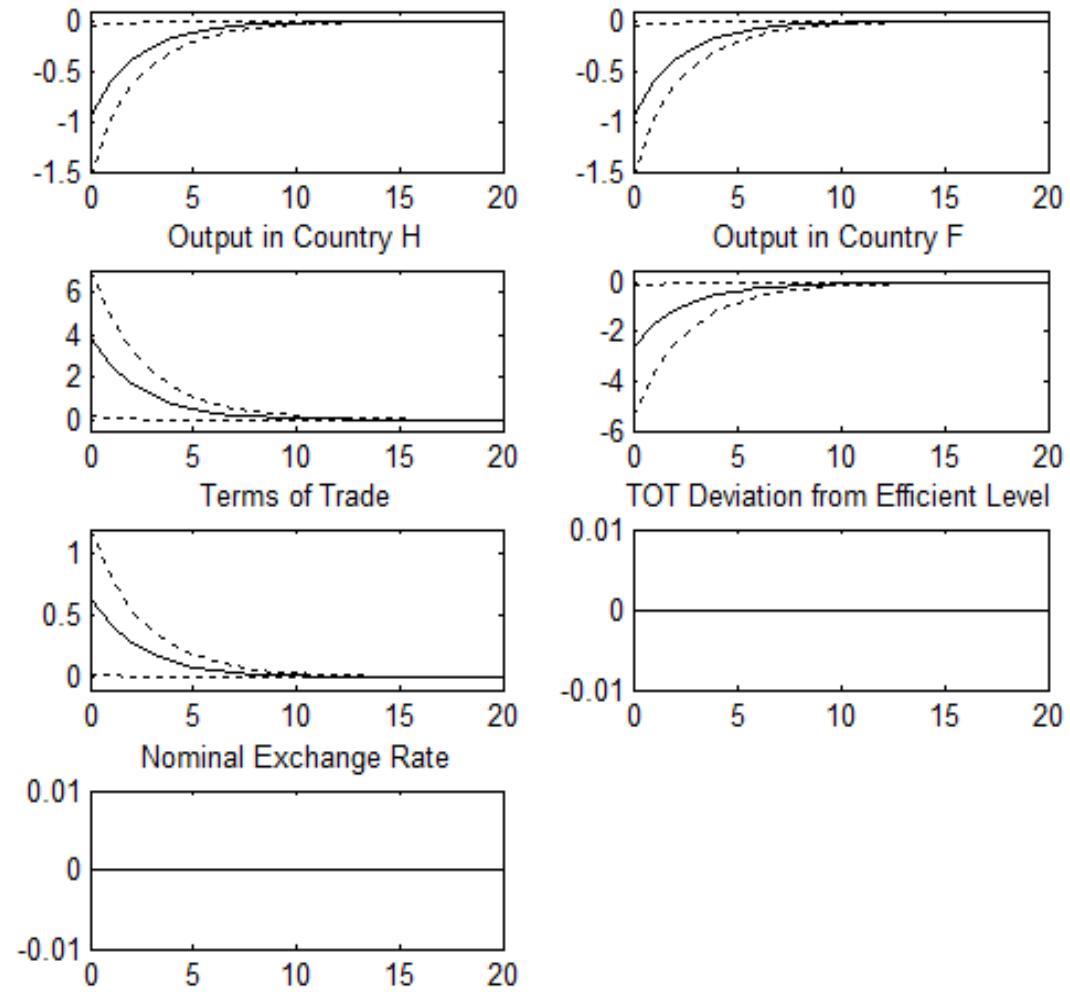
Figure 2: IRFs to productivity shocks in country $H$ in the PCP model
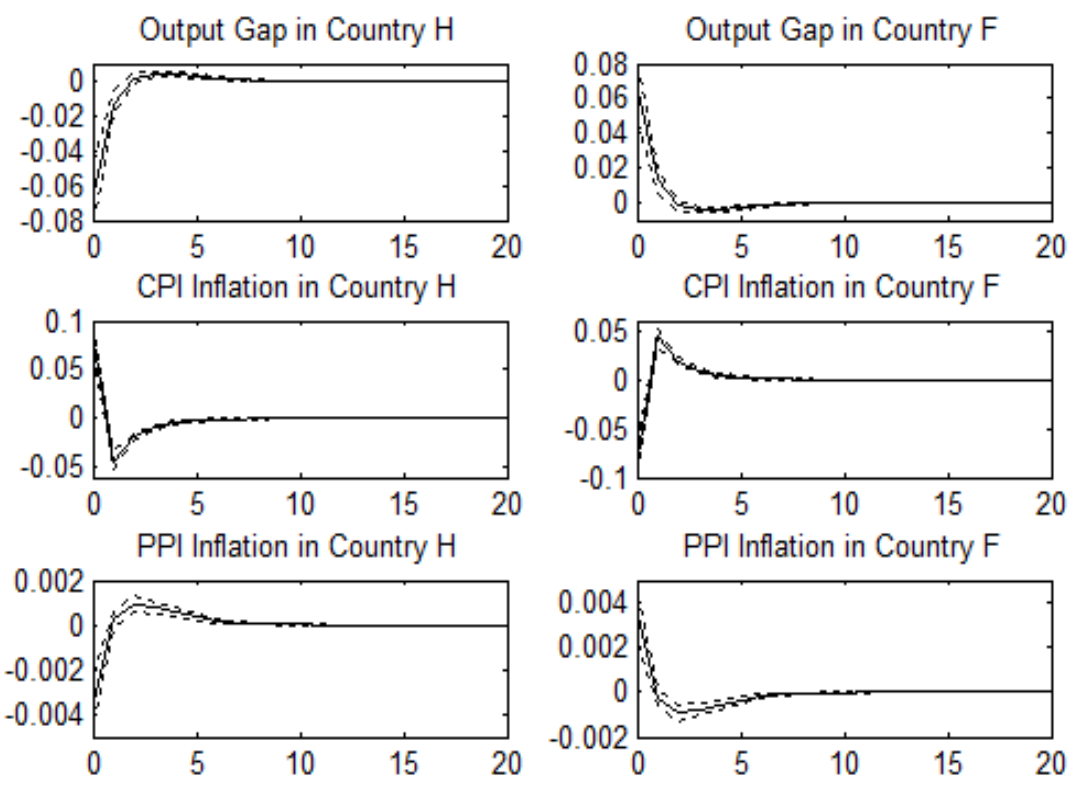

Nominal Interest Rate in Country $\mathrm{H}$

Nominal Interest Rate in Country F
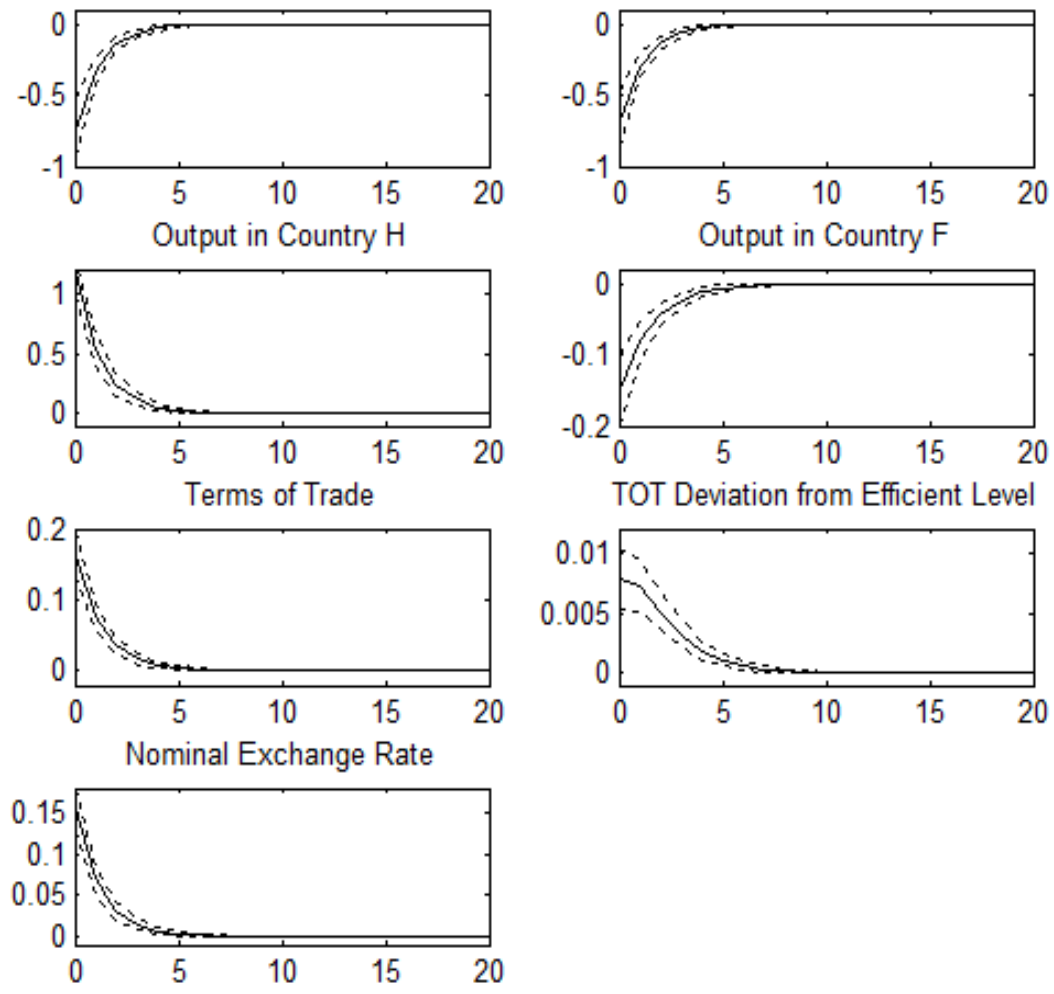